\title{
What is Reciprocity?
}

\section{A Review and Expert-based Classification of Cooperative Transfers}

\author{
Diego Guevara Beltran ${ }^{1}$, Jessica D. Ayers ${ }^{2}$, Andres Munoz ${ }^{1}$, Lee Cronk ${ }^{3}$, Athena Aktipis ${ }^{1}$ \\ 1Department of Psychology, Arizona State University, Tempe, AZ 85287-1104, United States. \\ 2Department of Psychological Science, Boise State University, Boise, ID, 83725-1715, USA. \\ ${ }^{3}$ Department of Anthropology, Rutgers University - New Brunswick, NJ 08901-1414, USA.
}

\begin{abstract}
Author Note
Funding. This work was conducted as part of The Human Generosity Project (humangenerosity.org), which has received support from the National Science Foundation, the John Templeton Foundation, and the Charles Koch Foundation. Any opinions, findings, conclusions or recommendations expressed in this material are those of the authors and do not necessarily reflect the views of our funders. Funding sources were not involved in the design of the study, analysis, writing, or in the decision to submit this manuscript.
\end{abstract}

Declarations of interest: none.

Corresponding author: Diego Guevara Beltran, Email: dguevar3@asu.edu.

Data availability: data is available here: https://osf.io/53pzi/.

This manuscript is available as a preprint: psyarxiv.com/cz3ue/.

Word count: 10,809

This manuscript is under review and may undergo additional revisions 


\begin{abstract}
After decades of research on the topic of reciprocity, there is still no consensus about the meaning of the term. Instead, there has been a proliferation of reciprocity terms with varied definitions, some of which overlap in ways that lead to confusion for scholars studying cooperation. In this paper, we provide a summary of 34 reciprocity terms and their definitions from across a variety of disciplines. We then report the results of a survey of cooperation experts spanning biology, anthropology, economics, sociology, and psychology $(N=85)$ about the extent to which they consider 30 of these definitions of reciprocity to be truly reciprocity. Experts also rated the extent to which they considered seventeen hypothetical scenarios to be examples of reciprocity. We used exploratory factor analysis and found that responses clustered around four categories of transfers: Balanced (e.g., Balanced reciprocity), Reputation-based (e.g., Generalized reciprocity), Debt-based (e.g., Calculated reciprocity), and Unconditional (e.g., Negative reciprocity). Although researchers agreed that the term reciprocity was useful and necessary, there was low agreement among scholars about what should be considered reciprocity. However, there was high agreement that unconditional transfers, which are characterized by a lack of expectations of repayment, should not be considered reciprocity. We propose that scholars of cooperation consider using these four categories when referring to cooperative transfers rather than using reciprocity terms in order to facilitate communication across disciplines, resolve issues related to ambiguous definitions of reciprocity, and provide a solution to the lack of consensus about what constitutes reciprocity.

Keywords. Cooperation, reciprocity, resource transfers.
\end{abstract}




\section{What is reciprocity?}

\section{A review and expert-based classification of cooperative transfers}

I learn to do service to another, without bearing him any real kindness, because I foresee, that he will return my service in expectation of another of the same kind, and in order to maintain the same correspondence of good offices with me and others. And accordingly, after I have serv'd him and he is in possession of the advantage arising from my action, he is induc'd to perform his part, as foreseeing the consequences of his refusal.

-David Hume, 1740, A Treatise of Human

Nature, Book III: Of Morals, part two, section five

\section{Introduction}

The concept of reciprocity has been part of the social sciences since at least the eighteenth century. The term became prominent in the twentieth century thanks to the work of scholars in various fields, from anthropology to economics to evolutionary biology. Bronisław Malinowski, one of the founders of sociocultural anthropology, argued that reciprocity was the basis of economic exchange, law, politics, and social structure in small-scale societies.

Describing his own field site in the Trobriand Islands, he wrote: "As a rule two communities rely upon each other in other forms of trading and other mutual services as well. Thus every chain of reciprocity is made all the more binding by being part and parcel of a whole system of mutualities" (1926:23). Marcel Mauss (Mauss, 2002), in his book The Gift, saw reciprocity as a fundamental principle in ancient and modern small-scale societies. Claude Levi-Strauss (1969) emphasized reciprocity's role in marriage systems in which descent groups exchange marriage partners over the generations. Economist Karl Polanyi argued that systems of economic distribution come in three types: reciprocity, redistribution, and the market (Polanyi, 1944). Marshall Sahlins (1965) and other anthropologists embraced Polanyi's framework, but Sahlins argued that reciprocity needed to be broken down into three types: generalized, balanced, and negative (see Table 1 for definitions). 
Robert Trivers (1971) brought the concept of reciprocity into evolutionary biology, in the process of coining the phrase "reciprocal altruism." Political scientist Robert Axelrod (1984; see also Axelrod \& Hamilton, 1981) combined reciprocity with game theory by holding a tournament in which different computer programs competed in a Prisoner's Dilemma game. The winning strategy, Tit-for-Tat (i.e., first cooperate, and then do whatever the other player did in the previous round) subsequently came to epitomize the meaning of reciprocity for many scholars (Carter 2014, Cronk and Leech 2013). Biologist Richard Alexander $(1977,1987)$ proposed the term indirect reciprocity to refer to situations in which the actor's reward for an act of kindness comes not from the recipient but rather from a third party observing the act. Indirect reciprocity was subsequently championed by Martin Nowak and Karl Sigmund as the key to the puzzle of human cooperation (Nowak \& Sigmund, 2005). And economist Herbert Gintis (2000) suggested the term strong reciprocity to refer to uncompensated acts of generosity favored by selection at the level of the group.

\section{Table 1}

Scholarly definitions of the term reciprocity

\begin{tabular}{|c|c|c|}
\hline Term & Citation & Description/definition \\
\hline Reciprocation & $\begin{array}{c}\text { Oxford English } \\
\text { Dictionary, in use as } \\
\text { early as } 1549\end{array}$ & $\begin{array}{c}\text { Action or practice of offering a response in kind, or of doing one } \\
\text { thing in return for another }\end{array}$ \\
\hline Reciprocity I & Malinowski 1926:40 & $\begin{array}{c}\text { "[A] chain of reciprocal gifts and countergifts, which in the long run } \\
\text { balance, benefiting both sides equally" }\end{array}$ \\
\hline Reciprocity II & Thurnwald 1932:106 & "To-day's giving will be recompensed by to-morrow's taking" \\
\hline $\begin{array}{l}\text { Heteromorphic } \\
\text { reciprocity }\end{array}$ & Gouldner 1960 & Exchange of things that are concretely different but of equal value \\
\hline $\begin{array}{l}\text { Homeomorphic } \\
\text { reciprocity }\end{array}$ & Gouldner 1960 & Exchange of things that are the same \\
\hline $\begin{array}{l}\text { Weak } \\
\text { reciprocity I* }\end{array}$ & Price 1962 & $\begin{array}{l}\text { Distribution of resources among individuals in producing groups in } \\
\text { the form of sharing }\end{array}$ \\
\hline
\end{tabular}




\begin{tabular}{|c|c|c|}
\hline $\begin{array}{l}\text { Strong } \\
\text { reciprocity I* }\end{array}$ & Price 1962 & $\begin{array}{l}\text { Distribution of resources among individuals in producing groups in } \\
\text { the form of exchange }\end{array}$ \\
\hline $\begin{array}{l}\text { Balanced } \\
\text { reciprocity }\end{array}$ & Sahlins 1965 & Transfers of equal value \\
\hline $\begin{array}{l}\text { Generalized } \\
\text { reciprocity I }\end{array}$ & Sahlins 1965 & Non-conditional sharing and giving of assistance \\
\hline $\begin{array}{l}\text { Negative } \\
\text { reciprocity I }\end{array}$ & Sahlins $1965^{1}$ & Acquisition of benefit without intent to repay \\
\hline Reciprocity III & $\begin{array}{l}\text { Levi-Strauss } 1969 \\
\quad(1949)\end{array}$ & $\begin{array}{l}\text { Gifts exchanged immediately or on the condition that return gifts } \\
\text { will be given in the future }\end{array}$ \\
\hline $\begin{array}{l}\text { Indirect } \\
\text { reciprocity }\end{array}$ & Alexander 1977 & Return is expected from someone other than recipient of benefit \\
\hline Tit-for-tat reciprocity & Axelrod 1984 & $\begin{array}{c}\text { Cooperate if other party cooperates, defect if other party defects } \\
\text { in iterated Prisoner's Dilemmas }\end{array}$ \\
\hline $\begin{array}{l}\text { Delayed } \\
\text { reciprocity }\end{array}$ & $\begin{array}{l}\text { Wiley \& Rabenold } \\
\qquad 1984^{2}\end{array}$ & Reciprocity with delay between initial transfer and repayment \\
\hline Reciprocal altruisma & Trivers $1985^{3}$ & $\begin{array}{l}\text { Acting altruistically towards another who has already acted } \\
\text { altruistically }\end{array}$ \\
\hline Reciprocal altruismb & Trivers 1985 & The trading of altruistic acts \\
\hline Pseudoreciprocity & Connor 1986 & $\begin{array}{l}\text { When "the return benefit for a beneficent act is a by-product or } \\
\text { incidental effect of egoistic behaviour by the recipient of the } \\
\text { beneficent act." }\end{array}$ \\
\hline Direct reciprocity & Alexander 1987 & Return is expected from the recipient of benefit \\
\hline $\begin{array}{l}\text { Upstream indirect } \\
\text { reciprocity }\end{array}$ & $\begin{array}{l}\text { Boyd \& Richerson } \\
1989\end{array}$ & $\begin{array}{c}\text { An act of altruism causes the recipient to perform a later act of } \\
\text { altruism in the benefit of a third party }\end{array}$ \\
\hline $\begin{array}{l}\text { Downstream } \\
\text { indirect reciprocity }\end{array}$ & $\begin{array}{l}\text { Boyd \& Richerson } \\
1989\end{array}$ & $\begin{array}{c}\text { The performer of an act of altruism is more likely to be the } \\
\text { recipient of a later act of altruism }\end{array}$ \\
\hline $\begin{array}{l}\text { Interpersonal } \\
\text { reciprocity }\end{array}$ & Burgoon et al. 1993 & $\begin{array}{l}\text { "... one responds, in a similar direction, to a partner's behaviors } \\
\text { with behaviors of comparable functional value." }\end{array}$ \\
\hline
\end{tabular}

\footnotetext{
${ }^{1}$ Sahlins incorrectly attributed this term to Gouldner (1960), who actually used the phrase "negative norms of reciprocity" to refer to instances of homeomorphic reciprocity in which the thing exchanged is some sort of harm (e.g., an eye for an eye).

${ }^{2}$ Although this is the earliest scholarly reference to the phrase "delayed reciprocity," anthropologists have long known that a delay between transfers is an important part of many gift-giving systems (e.g., Mauss 1922).

${ }^{3}$ Trivers' original article on reciprocal altruism was published in 1971, but in that article he did not define the term. These definitions are from his 1985 textbook.
} 


\begin{tabular}{|c|c|c|}
\hline $\begin{array}{l}\text { Positive } \\
\text { reciprocity }\end{array}$ & Suranovic 2000 & $\begin{array}{l}\text { An action that has a positive effect upon someone else is } \\
\text { reciprocated with an action that has approximately equal positive } \\
\text { effect upon another }\end{array}$ \\
\hline $\begin{array}{l}\text { Negative } \\
\text { reciprocity II }\end{array}$ & Suranovic 2000 & $\begin{array}{l}\text { An action that has a negative effect upon someone else is } \\
\text { reciprocated with an action that has approximately equal negative } \\
\text { effect upon another }\end{array}$ \\
\hline $\begin{array}{l}\text { Risk reduction } \\
\text { reciprocity }\end{array}$ & $\begin{array}{l}\text { Bliege Bird et al. } \\
\qquad 2002\end{array}$ & Giving with the expectation of equivalent return \\
\hline $\begin{array}{l}\text { Strong } \\
\text { reciprocity II }\end{array}$ & Gintis 2000 & $\begin{array}{l}\text { Non-conditional altruism, including costly punishment, favored by } \\
\text { group selection }\end{array}$ \\
\hline $\begin{array}{l}\text { Symmetry-based } \\
\text { reciprocity }\end{array}$ & $\begin{array}{l}\text { Brosnan \& de Waal } \\
2002\end{array}$ & $\begin{array}{l}\text { Mutual affection between two parties prompts similar behavior in } \\
\text { both directions without the need to keep track of give-and-take, so } \\
\text { long as the relationship remains satisfactory (we're buddies) }\end{array}$ \\
\hline $\begin{array}{l}\text { Attitudinal } \\
\text { reciprocity }\end{array}$ & $\begin{array}{l}\text { Brosnan \& de Waal } \\
2002\end{array}$ & $\begin{array}{l}\text { Parties mirror one another's attitudes, exchanging favors on the } \\
\text { spot (if you're nice, l'll be nice) }\end{array}$ \\
\hline $\begin{array}{l}\text { Calculated } \\
\text { reciprocity }\end{array}$ & $\begin{array}{l}\text { Brosnan \& de Waal } \\
2002\end{array}$ & $\begin{array}{l}\text { Individuals keep track of the benefits they exchange with } \\
\text { particular partners, which helps them decide to whom to return } \\
\text { favor (what have you done for me lately?) }\end{array}$ \\
\hline $\begin{array}{l}\text { Generalized } \\
\text { reciprocity II }\end{array}$ & Pfeiffer et. al. 2005 & $\begin{array}{l}\text { General tendency to be altruistic to others when others have been } \\
\text { altruistic to you }\end{array}$ \\
\hline $\begin{array}{l}\text { Network } \\
\text { reciprocity }\end{array}$ & Nowak 2006 & Non-conditional altruism favored by selection on social networks \\
\hline $\begin{array}{l}\text { Contingent } \\
\text { reciprocity }\end{array}$ & Gurven 2006 & Giving contingent on past giving \\
\hline Serial reciprocity* & Moody 2008 & $\begin{array}{l}\text { "... when people reciprocate for what they have received ... } \\
\text { by providing something to a third party, regardless of whether } \\
\text { a return is also given, or makes its way back to, the original giver." }\end{array}$ \\
\hline $\begin{array}{l}\text { Weak } \\
\text { reciprocity II }\end{array}$ & Guala 2011 & $\begin{array}{c}\text { In contrast to strong reciprocity, this requires that actors receive a } \\
\text { benefit }\end{array}$ \\
\hline $\begin{array}{l}\text { Pay-it-forward } \\
\text { reciprocity* }\end{array}$ & Horita et al., 2016 & Forward kindness received from others to strangers \\
\hline $\begin{array}{l}\text { Social } \\
\text { reciprocity* }\end{array}$ & Floyd et al., 2018 & $\begin{array}{l}\text { Mutual exchange of goods, services and support among } \\
\text { individuals, allowing for the distribution and augmentation } \\
\text { of human agency in ways that individuals could not achieve alone }\end{array}$ \\
\hline
\end{tabular}

Note. This table summarizes the first uses of various reciprocity terms from the initial use of "reciprocation" to the current uses of a wide range of reciprocity terms. * $=$ definition was not included in the survey. 
As can be seen in Table 1, this is just a small part of the history of the term. By our count, scholars have proposed a total of thirty-four different definitions of reciprocity (excluding Reciprocation, which is found in the Oxford English Dictionary). In some instances, the same term has been used by different scholars to mean different things (e.g., generalized, weak, strong, and negative reciprocity). Many terms, such as upstream indirect reciprocity, serial reciprocity, pay-it-forward reciprocity, weak reciprocity I, and generalized reciprocity I share substantial overlapping meanings. Some reciprocity terms are in widespread use (e.g., indirect reciprocity) and others are less common in the literature (e.g., homeomorphic reciprocity). Some types of reciprocity resemble the kind of back-and-forth exchange imagined by Malinowski and other early reciprocity scholars, while others do not. For example, neither generalized reciprocity nor strong reciprocity necessarily includes any return benefit to the original actor.

For scientific communication to be effective, the concepts scientists use must be clearly defined, and there must be a consensus among scientists regarding those definitions. The diversity of reciprocity-related concepts creates an opportunity to explore the degree to which there is a consensus among scientists about them. To that end, we conducted a survey of scholars who have contributed to the study of reciprocity and other forms of cooperation. The survey presented the various definitions of reciprocity terms, as well as vignettes about reciprocal scenarios, and asked scholars how well each one exemplified what they mean by the term "reciprocity." Although Table 1 shows 35 reciprocity terms, our survey included 30 . This discrepancy stems from three things. First, Trivers (1985) used two sentences to define reciprocal altruism, and we treated them as separate definitions in the survey. Second, we were unaware of serial reciprocity (Moody, 2008), social reciprocity (Floyd, 2018), and pay-it-forward reciprocity (Horita et al., 2016) when we designed the survey. Finally, we failed to include the first definition of strong reciprocity I (Price, 1962), and weak reciprocity I (Price, 1962), due to an oversight. 


\section{Method}

\subsection{Participants}

We compiled a list of emails of academics who have published articles in the areas of cooperation and reciprocity. We searched for peer-reviewed articles that had either the word "reciprocity" or "cooperation" in their titles. We selected articles from the fields of psychology, biology, anthropology, economics, sociology, and communications, identifying a total of 127 peer-reviewed articles. We retrieved 222 valid email addresses for the authors and co-authors (seven email addresses were no longer in service). We then posted our survey on Facebook and Twitter to recruit reciprocity and cooperation researchers we may have missed during the web scraping process. Lastly, we employed snowball sampling, allowing participants the opportunity to share the survey with other academics.

Combined, 130 people completed the survey. Forty-five participants were excluded because they indicated they were not researchers, at which point the survey ended $(n=27)$, or because they had $50 \%$ or more missing responses $(n=18)$. After removing these participants, our effective sample size was 85 cooperation/reciprocity researchers (49.4\% men, $10.6 \%$ women, $40.0 \%$ no-response). We recruited 43 via email, 18 via social media, and three via snowball sampling (21 participants did not indicate how they were recruited). Overall, sample characteristics (see Table 2) indicate that participants were experienced researchers who were familiar with the literature on reciprocity and cooperation. 
Table 2

Sample characteristics

\begin{tabular}{ccccccc}
\hline Academic training & Freq. & $\%$ & Interest in reciprocity & Freq. & $\%$ \\
\hline PhD & 63 & 74.1 & Primary interest & 8 & 9.4 \\
Master's & 2 & 2.4 & Top two interests & 10 & 11.8 \\
Bachelor's & 1 & 1.2 & Top five interests & 37 & 43.5 \\
No-response & 18 & 21.2 & Not among primary interests & 12 & 14.1 \\
& & & no-response & 18 & 21.2 \\
\hline Academic field & Freq. & $\%$ & Interest in cooperation & Freq. & $\%$ \\
\hline Biology & 16 & 18.8 & Primary interest & 17 & 20.0 \\
Psychology & 16 & 18.8 & Top two interests & 23 & 27.1 \\
Economics & 12 & 14.1 & Top five interests & 22 & 25.9 \\
Anthropology & 6 & 7.1 & Not among primary interests & 5 & 5.9 \\
Sociology & 5 & 5.9 & no-response & 18 & 21.2 \\
\cline { 4 - 7 } Mathematics & 3 & 3.5 & Publications & Freq. & $\%$ \\
\cline { 4 - 7 } Political Science & 2 & 2.4 & 100 or more & 10 & 11.8 \\
Communications & 2 & 2.4 & $50-99$ & 17 & 20.0 \\
Computer Science & 2 & 2.4 & 30 to 49 & 9 & 10.6 \\
Philosophy & 2 & 2.4 & 20 to 29 & 6 & 7.1 \\
Evolutionary Social Science & 1 & 1.2 & 10 to 19 & 12 & 14.1 \\
No-response & 18 & 21.2 & 10 & 11.8 \\
& & & No-response & 21 & 24.7 \\
\hline & & & &
\end{tabular}

\subsection{Measures and procedure}

The survey consisted of three blocks. In the first block, participants were asked the extent to which the term reciprocity is useful in the scientific literature $(1=$ not at all useful, $7=$ very useful), the extent to which there is consensus about the use of the term reciprocity among 
academics within their field, the extent to which there is consensus about the use of the term reciprocity among academics in other disciplines, and the extent to which there is consensus about the use of the term reciprocity among non-academics $(1=$ no consensus, $7=$ absolute consensus). In the second block, participants were presented with thirty definitions of reciprocity taken from the scholarly literature (e.g., a situation where today's giving will be recompensed by tomorrow's taking), and were asked to rate the extent to which they thought each definition presented was reciprocity ( $1=$ definitely not reciprocity, $7=$ definitely reciprocity). Additionally, participants were given the opportunity to describe, in an open-ended format, each of the definitions (i.e., What word would you use to describe this? (optional)). Participants were not shown the technical term (e.g., Reciprocal altruism).

In the third block, participants were shown seventeen hypothetical scenarios that some might consider reciprocity. For each scenario, participants were asked to rate the extent to which they thought the scenario presented was reciprocity $(1=$ definitely not reciprocity, $7=$ definitely reciprocity). And, again, participants were given the opportunity to describe each of the definitions (i.e., What word would you use to describe this? (optional)). We created some of these scenarios to specifically map onto definitions from the scholarly literature. For example, Homeomorphic Reciprocity (i.e., exchange of things that are the same or of equal value) (Gouldner, 1960) was represented by "Skyler is hungry and has no food. Chris gives Skyler some bread. On the next day, Chris is hungry and has no food. Skyler gives Chris some bread." However, some of the hypothetical scenarios could map onto more than one scholarly definition. For example, Reciprocity II (i.e., today's giving will be recompensed by tomorrow's taking) (Thurnwald, 1932) could be represented by the scenario described above based on the definition of Homeomorphic Reciprocity as well as this scenario based on the definition of Delayed Reciprocity: “Skyler gives Chris some juice. Three months later, Chris gives Skyler some bread." Lastly, we added some scenarios that did not directly correspond to any current definition of reciprocity. For example: "Chris smiles at Skyler and Skyler smiles back at Chris." 


\subsection{Transparency, openness, and data analyses}

This study was not preregistered. We report sample size considerations, measures, and data exclusions. Data and analysis code are available here (osf.io/53pzi/?viewonly). We ran factor analyses with the Psych package for R Studio V. 1.3.1 (Revelle, 2018), and SPSS V.28. This study was approved by [redacted].

\section{Results}

As shown in Table 2, 18 participants failed to report their academic training, current academic field, academic interest in cooperation and reciprocity, and number of publications (an additional three participants failed to report their number of publications but reported on the other items). Because these participants failed to report on the items assessing expertise, we were concerned that these participants may not truly be experts, and we therefore conducted additional analyses removing these 18 participants to assess the robustness of our results.

\subsection{Perceived usefulness and need for the term reciprocity}

Researchers indicated on a 7-point Likert scale that the term reciprocity was useful ( $M=$ $5.89, S D=1.07)$, and necessary $(M=5.80, S D=1.30)$, and a one-way ANOVA showed that anthropologists, biologists, economists, psychologists, and sociologists believe the term reciprocity is equally useful $\left(F(4,50)=0.74, p=0.57, \eta^{2}=0.05\right)$, and necessary $(F(4,50)=$ $\left.0.57, p=0.68, \eta^{2}=0.04\right)$.

\subsection{Perceived consensus of the term reciprocity}

Paired-samples $t$-tests showed that researchers believe there is more consensus about the use of the term reciprocity among academics in their own academic fields $(M=4.67, S D=$ 1.16) than among academics in other fields $\left(t(82)=9.06, p<0.001, M_{\text {diff }}=0.99, \mathrm{Cl}_{95 \%}[0.77\right.$, $1.20], d=0.99)$, or among the public $\left(t(82)=4.99, p<0.001, M_{\text {diff }}=0.87, \mathrm{Cl}_{95 \%}[0.52,1.21], d=\right.$ $0.55)$; but researchers believe there is equal consensus about the use of the term reciprocity among the public $(M=3.81, S D=1.27)$ compared to among other academic fields $(M=3.69$, 
$\left.S D=1.21, t(82)=-0.73, p=0.47, \mathrm{Cl}_{95 \%}[-0.45,0.21], d=-0.08\right)$. Supplemental analyses show that results did not change after removing the 18 participants who failed to report on items assessing expertise (Table S1). A sensitivity analysis in G*Power 3 (Faul et al., 2007) for a twotailed paired-samples $t$-test $(n=82, \alpha=0.05$, and $1-\beta=0.80)$ showed that we were adequately powered to detect an effect as small as $d=0.28$.

Anthropologists, biologists, economists, psychologists, and sociologists did not differ in the extent to which they believed there was consensus about the use of the term reciprocity among academics in their own fields $\left(F(4,50)=2.06, p=0.10, \eta^{2}=0.14\right)$, among the public $\left(F(4,50)=0.54, p=0.70, \eta^{2}=0.04\right)$, or among academics in other fields $(F(4,50)=2.69, p=$ $0.04, \eta^{2}=0.18$ ). Post-hoc pairwise comparisons with least squares difference suggest that sociologists believed that there was greater consensus about the use of the term reciprocity in other academic fields than anthropologists $\left(M_{\text {diff }}=1.97, p=0.01, \mathrm{Cl}_{95 \%}[0.54,3.39], d=1.74\right)$, and biologists $\left(M_{\text {diff }}=1.74, p=0.01, \mathrm{Cl}_{95 \%}[0.53,2.95], g=1.44\right)$. However, these comparisons do not survive Bonferroni correction ( $p$ 's $>0.10$ ).

\subsection{Scholarly definitions of reciprocity}

\subsubsection{Exploratory factor analyses (scholarly definitions)}

To explore whether researchers' definitions of reciprocity differed within or between academic fields, we first ran exploratory factor analyses on the extent to which researchers believe each of the thirty definitions is truly reciprocity. We allowed factors to be correlated with one another, employing maximum likelihood extraction and listwise deletion for missing data ( $n$ $=70$ ). Based on Eigenvalues and visual inspection of scree plots extracted from a principal component analysis, we ran exploratory factor analyses with one, two, three, four, and fivefactor solutions. A four-factor solution accounting for $46 \%$ of the variance yielded the most interpretable results $\left(\chi^{2}(321)=350.55, p<0.12, \mathrm{TLI}=0.93, \mathrm{RMSR}=0.06, \mathrm{RMSEA}=0.03\right.$, $\left.\mathrm{Cl}_{90 \%}[0,0.06]\right)$ (Table S2; Figure 1). Sample size recommendations for factor analyses range from $N=50-75$ when extracting four factors, when there is a ratio of 7 variables per factor 
extracted (our case was 7.5 variables per factor), and when communalities are wide (i.e., the proportion of variance in each variable explained by its corresponding latent factor range from 0.20-0.80) (Mundfrom et al., 2005). Given these considerations, our sample size is within the recommended range. We found the same 4-factor solution after removing the 18 participants who failed to report on items assessing expertise (Table S3).

Eight definitions loaded on the first factor, which we labeled "Balanced Transfers," accounted for $14 \%$ of the variance, and included such definitions as Heteromorphic Reciprocity: exchange of things that are concretely different but of equal value (factor loading $=0.90$ ), and Balanced Reciprocity: transfers of equal value (factor loading $=0.67$ ).

Six definitions loaded on the second factor, which we labeled "Reputation-based Transfers," accounted for $13 \%$ of the variance, and included such definitions as Reciprocal Altruisma: acting altruistically towards another who has already acted altruistically (factor loading $=0.87)$, and Indirect Reciprocity: when return is expected from someone other than the recipient of benefit (factor loading $=0.53$ ).

Five definitions loaded on a third factor, which we labeled "Debt-based Transfers", accounted for $11 \%$ of the variance, and included such definitions as Direct Reciprocity: when return is expected from the recipient of the benefit (factor loading $=0.80$ ), and Calculated Reciprocity: when individuals keep track of the benefits they exchange with particular partners, which helps them decide to whom to return favors (factor loading $=0.58$ ).

Four definitions loaded on the fourth factor, which we labeled "Unconditional Transfers," accounted for $7 \%$ of the variance, and included such definitions as Network Reciprocity: nonconditional altruism favored by selection on social networks (factor loading $=0.68$ ), and Generalized Reciprocity I: non-conditional sharing and giving of assistance (factor loading = 0.69).

The Balanced Transfers factor was positively correlated with Debt-based Transfers ( $r=$ 0.40), Reputation-based Transfers $(r=0.27)$, and Unconditional Transfers $(r=0.15)$. The 
Reputation-based Transfers factor was positively correlated with Debt-based Transfers ( $r=$ 0.32), and Unconditional Transfers $(r=0.21)$, but the Debt-based Transfers factor did not correlate with the Unconditional Transfers factor $(r=0.01)$.

\section{Figure 1}

Loadings from exploratory factor analysis of the scholarly definitions of the term reciprocity

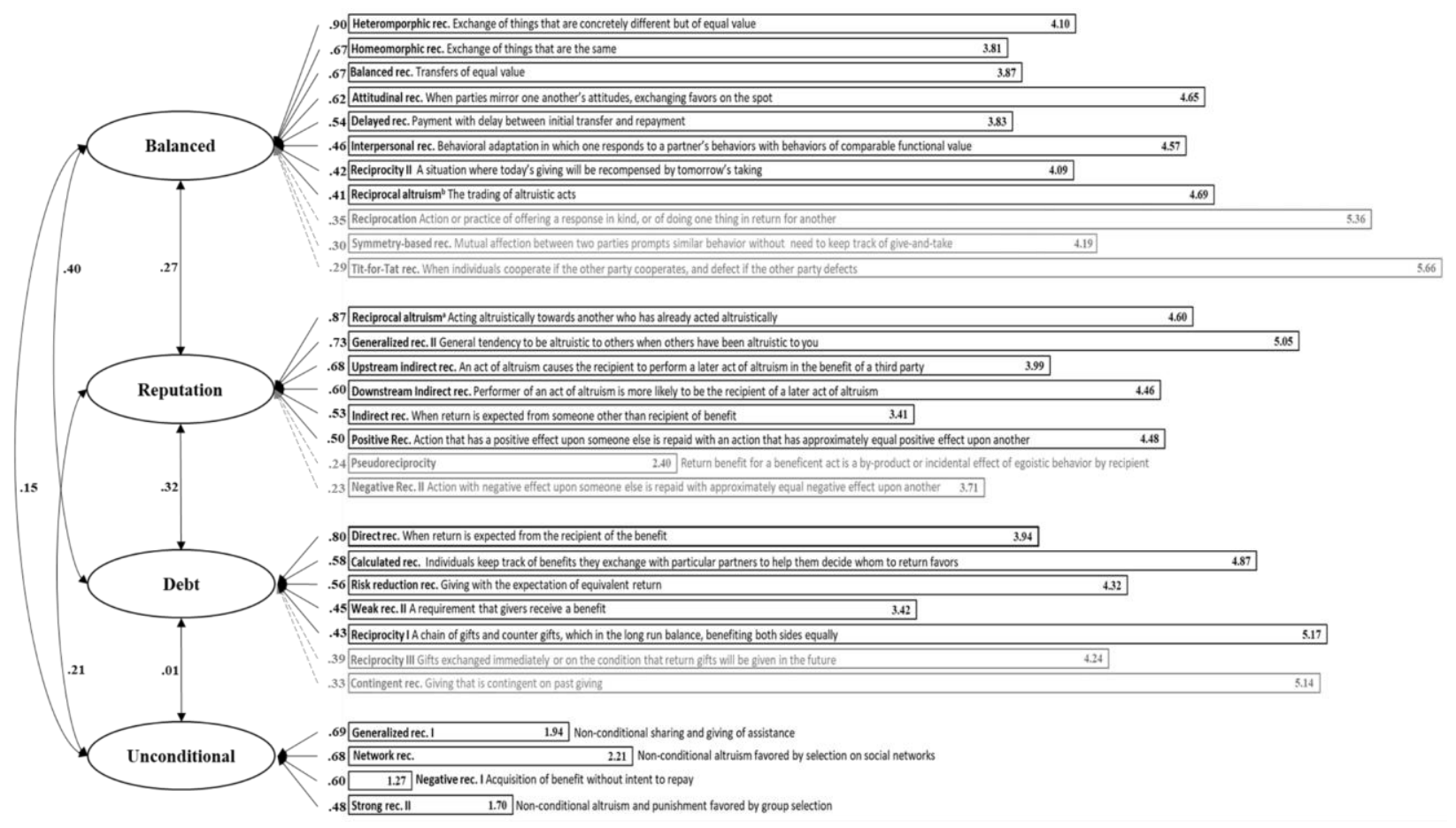

Note. The size of the bars represents mean scores regarding whether survey respondents agreed that the definition is reciprocity ( $1=$ definitely not reciprocity, $7=$ definitely reciprocity). Solid lines indicate factor loadings $>=0.40$; dashed lines indicate factor loadings $<0.40$. Responses clustered along three dimensions: Balanced Transfers, Conditional Transfers, and Unconditional Transfers.

\subsubsection{Reciprocity ratings based on extracted factors (scholarly definitions)}

Based on the four-factor solution shown in Figure 1, we computed mean scores for the Balanced, Reputation-based, Debt-based, and Unconditional Transfers factors across all 
researchers, and within each of the main five represented academic fields. Variables with loadings lower than 0.40 are generally considered to not contribute meaningfully to latent factors (Knekta et al., 2019) and were thus excluded from composite scores.

We first tested whether researchers considered certain dimensions of transfers to be more reciprocity than others. Paired-samples $t$-tests (Table 3) show that researchers did not differ in the extent to which they considered Balanced, Reputation-based, and Debt-based Transfers to be reciprocity ( $p$ 's $>0.38$ ). However, researchers considered Unconditional Transfers to be less reciprocity than all other three reciprocity factors (Cohen's $d$ 's $=1.50$ to 1.70). Supplemental analyses show these results do not change after removing participants who failed to report items assessing academic expertise (Table S4). A sensitivity analysis (pairedsamples $t, n=69, \alpha=0.05,1-\beta=0.80$ ) revealed that we were adequately powered to detect effects as small as $d=0.34$.

\section{Table 3}

Paired-samples $t$-tests of reciprocity ratings (scholarly definition factors)

\begin{tabular}{lcccccc}
\hline Comparison & $t(\mathrm{df})$ & $p$ & $M_{\text {dift }}$ & $95 \% \mathrm{Cl}$ & $d$ \\
\hline Balanced - Reputation & $-0.87(69)$ & 0.39 & -0.17 & -0.56 & 0.22 & -0.10 \\
Balanced - Debt & $-0.82(69)$ & 0.41 & -0.13 & -0.44 & 0.18 & -0.10 \\
Balanced - Unconditional & $13.22(69)$ & $<0.001$ & 2.40 & 2.03 & 2.76 & 1.58 \\
Reputation - Debt & $0.33(70)$ & 0.75 & 0.06 & -0.30 & 0.41 & 0.04 \\
Reputation - Unconditional & $14.37(70)$ & $<0.001$ & 2.57 & 2.22 & 2.93 & 1.70 \\
Debt - Unconditional & $12.73(71)$ & $<0.001$ & 2.52 & 2.13 & 2.92 & 1.50 \\
\hline
\end{tabular}

\subsubsection{Reciprocity ratings based on extracted factors across fields (scholarly definitions)}

We then tested whether researchers differed in their ratings of reciprocity across academic fields (Table S5). Because a test of homogeneity of variance showed that there were 
unequal variances across academic fields for ratings of Reputation-based Transfers (Lavene's Statistic $=4.47, p=0.004$ ), we report the Welch's $F$ test for this factor. One-way ANOVAs showed that researchers across fields did not differ in the extent to which they rated Unconditional Transfers $\left(F(4,50)=1.71, p=0.16, \eta^{2}=0.12\right)$ or Reputation-based Transfers (Welch's $\left.F(4,15.25)=0.53, p=0.71, \omega^{2}=-0.03\right)$ to be reciprocity.

For Balanced Transfers $\left(F(4,50)=2.58, p=0.048, \eta^{2}=0.17\right)$, post-hoc pairwise comparisons with least squares difference suggest that economists believed this factor to be less reciprocity than did biologists $\left(M_{\text {diff }}=-1.51, p=0.01, \mathrm{Cl}_{95 \%}[-2.64,-0.38], g=1.08\right)$, psychologists $\left(M_{\text {diff }}=-1.49, p=0.01, \mathrm{Cl}_{95 \%}[-2.62,-0.36], g=1.19\right)$, and sociologists $\left(M_{\text {diff }}=-\right.$ $\left.1.75, p=0.03, \mathrm{Cl}_{95 \%}[-3.32,-0.17], g=1.17\right)$. However, neither of these comparisons survived Bonferroni correction ( $p$ 's $>0.09$ ).

For Debt-based Transfers $\left(F(4,50)=2.65, p=0.04, \eta^{2}=0.17\right)$, post-hoc pairwise comparisons with least squares difference suggest that economists believed this factor to be less reciprocity than did psychologists $\left(M_{\text {diff }}=-1.39, p=0.02, \mathrm{Cl}_{95 \%}[-2.61,-0.17], g=0.95\right)$ and sociologists $\left(M_{\text {dift }}=-2.53, p=0.004, \mathrm{Cl}_{95 \%}[-4.24,-0.83], g=1.91\right)$. However, only the comparison between economists and sociologists survived Bonferroni correction $(p=0.04)$.

\subsubsection{Researcher agreement about the term reciprocity (scholarly definitions)}

To further explore the extent to which researchers agreed or disagreed that the thirty definitions shown were or were not reciprocity, we transformed responses to reflect three categories: $1-3=$ Is not reciprocity, $4=$ Somewhat reciprocity, and 5-7 = Is reciprocity. We then ran a series of Fleiss' Kappas for each definition with the RSRP software (Release 7.6) (Zaiontz, 2020). Fleiss' Kappa is a test of inter-rater agreement for categorical responses, ranging from 0 (no agreement) to 1 (full agreement). A Fleiss' Kappa of 0.75 or above is typically considered an acceptable level of agreement (Fleiss \& Cohen, 1973). No definitions reached an acceptable level of agreement regarding what should be considered reciprocity. Two definitions reached an acceptable level of agreement that they should not be considered 
reciprocity: Negative Reciprocity I $\left(k=0.92, \mathrm{Cl}_{95 \%}[0.89,0.96]\right)$ and Strong Reciprocity II $(k=$ $\left.0.83, \mathrm{Cl}_{95 \%}[0.80,0.85]\right)$ (Table S6). We found the same results after removing participants who failed to report items assessing academic expertise $(n=67)$ : Negative Reciprocity I ( $k=0.91$, $\left.\mathrm{Cl}_{95 \%}[0.87,0.95]\right)$ and Strong Reciprocity II $\left(k=0.83, \mathrm{Cl}_{95 \%}[0.80,0.86]\right)$ were not considered to be reciprocity; all other definitions did not reach an acceptable level of agreement $(k$ 's $<0.71)$.

\subsubsection{Researcher disagreement about the term reciprocity (scholarly definitions)}

Given the low rate of agreement regarding whether the scholarly definitions were considered reciprocity, we looked at the open-ended responses participants provided for the scholarly definitions with the lowest agreement $(n=8, k$ 's $<0.30)$. Five of these definitions (i.e., Balanced Reciprocity, Delayed Reciprocity, Homeomorphic Reciprocity, Heteromorphic Reciprocity, and Reciprocity III) came from definitions that loaded on the Balanced Transfers factor. Given that these responses were optional, only a few participants provided open-ended responses. For these five definitions, for example, only 13-22 participants provided open-ended responses, and no participant provided an open-ended response to all five definitions. While we are unable to run inferential statistics on these responses, we looked at common themes and issues that researchers raised.

The most common theme (55\%, 49 out 89 observations) surrounding these definitions were words relating to market-like transactions such as "market exchange", "swap/swapping," "debt," "credit," "loan/lending," "trade," "barter," "investment," and "bargaining." In contrast to this common theme, other researchers raised some potential grounds for disagreement. Potential grounds for disagreement included (1) the number of agents involved in the transfers ("between a pair of actors? Then yes [it is reciprocity]"); (2) whether the transfers hold positive value or utility ("reciprocity if the value is positive/the things are useful"; "I don't like the 'taking' at the end, which doesn't make this reciprocity. For reciprocity, this should be 'A situation where today's giving will be recompensed by tomorrow's RECEIVING'”); (3) whether the transfer involved intent on part of the agents ("Depends on intent. This could be rewarding good 
behavior or simply a mutually beneficial transaction"; "This [definition] sounds like a simple exchange. No one gave first with the hope of making the other feel more obligated to give back in the future"); and (4) whether a transfer incurs risk ("In the reciprocity world, there needs to be a risk that the other person might not reciprocate. There is no risk here").

Another definition with one of the lowest rates of agreement was Weak Reciprocity II ( $A$ requirement that givers receive a benefit), which loaded on the Debt-based Transfers factor. We received 15 open-ended responses for this definition, with no clear common theme. Potential grounds for disagreement included (1) that reciprocity should include both positive and negative transfers ("No [it is not reciprocity] because negative reciprocity is also reciprocity"); (2) that the transfer does not involve risk ("This is not reciprocity. The requirement makes this a contract, where there is no real risk that a person won't give back"); (3) whether the recipient of the transfer returns the favor directly ("This is reciprocity if the giver receives its benefit from the original receiver"); and (4) lack of clarity.

Symmetry-based Reciprocity (When mutual affection between two parties prompts similar behavior in both directions without the need to keep track of give-and-take, so long as the relationship remains satisfactory) also received low researcher agreement, and did not load onto any of the factors extracted from the scholarly definitions. We received 17 open-ended responses for this definition. The most common theme (41.2\% of observations) emerged from words that described close or communal relationships (e.g., "friendship," "commitment," and "communal relationship"). Although no researcher provided potential grounds for disagreement, we can see that researchers who provided these words gave ratings of reciprocity ranging from the lowest to the highest, suggesting that the disagreement may in part be due to differences regarding whether transfers among close or highly committed relationships are reciprocity.

Lastly, Negative Reciprocity II (An action that has a negative effect upon someone else is repaid with an action that has approximately equal negative effect upon another) received low agreement and did not load on any of the scholarly definitions factors. We received 26 open- 
ended responses for this definition. Three common themes emerged from the words "spite" ( $11.5 \%$ of responses) and "negative reciprocity" ( $23.1 \%$ of responses) and from words such as "vengeance," "revenge," and "punishment/retaliation" (23.1\% of responses). Potential grounds for disagreement included (1) whether researchers believe spite, negative reciprocity, and retaliation should be considered reciprocity, (2) whether the transfers involved a cost ("[it is reciprocity] If it is costly"), and (3) whether the transfer is returned ("[ls reciprocity] But only if 'another' is the original actor whom 'someone else' repays").

\subsection{Hypothetical scenarios of reciprocity}

\subsubsection{Exploratory factor analyses (social scenarios)}

We were also interested in exploring the extent to which experts considered some social scenarios --devoid of academic jargon-- to be reciprocity. Based on Eigenvalues and visual inspection of scree plots extracted from a principal component analysis, we ran exploratory factor analyses with one, two, three, four, and five-factor solutions. We allowed factors to be correlated with one another employing maximum likelihood extraction and listwise deletion for missing data $(n=76)$. Our sample size was within the recommended range to extract 1-3 factor solutions (Mundfrom et al., 2005). However, a four-factor solution accounting for $42 \%$ of the variance yielded the most interpretable results $\left(\chi^{2}(74)=102.64, p<0.01, \mathrm{TLI}=0.80, \mathrm{RMSR}=\right.$ 0.06, RMSEA $\left.=0.07, \mathrm{Cl}_{90 \%}[0.03,0.10]\right)($ Table S7; Figure 2)

The difference between the three- and four-factor solutions is that two scenarios akin to reputation-based transfers, which did not load onto another factor in the three-factor solution (Table S8), loaded onto a fourth factor in the four-factor solution. We report the four-factor solution below to achieve greater congruence with the factors extracted from the scholarly definitions.

Six scenarios loaded on the first factor, "Balanced/Debt-based Transfers," which accounted for $15 \%$ of the variance and included scenarios such as Skyler gives Chris some 
juice. Three months later, Chris gives Skyler some bread (factor loading $=0.70$ ). Two scenarios loaded on the factor "Retaliation," which accounted for $10 \%$ of the variance, and included Chris punches Skyler and Skyler punches Chris in response (factor loading $=0.96$ ), and Chris steals Skyler's bread. Three months later, Skyler steals Chris' bread (factor loading $=0.75$ ).

Four scenarios loaded on a third factor, "Unconditional Transfers," which accounted for $10 \%$ of the variance and included such scenarios as Skyler is hungry and has no food. Chris gives Skyler some bread. Skyler gives Chris a smile (factor loading $=0.70$ ). Two items that loaded on the fourth factor, "Reputation-based Transfers," accounted for $6 \%$ of the variance. This factor included Chris gives Skyler some bread and Alex sees the exchange taking place. Then, Alex gives Chris some bread (factor loading = 0.61); and Chris gives Skyler some bread. Then, Skyler gives Alex some bread (factor loading $=0.58$ ).

Balanced/Debt-based Transfers was positively correlated with Retaliation $(r=0.27)$, Unconditional Transfers $(r=0.33)$, and Reputation-based Transfers $(r=0.22)$. Retaliation was positively correlated with Unconditional Transfers $(r=0.24)$, but not with Reputation-based Transfers $(r=0.02)$. Lastly, Unconditional Transfers was positively correlated with Reputationbased Transfers $(r=0.19)$. 


\section{Figure 2}

Loadings from exploratory factor analysis of the hypothetical scenarios of reciprocity

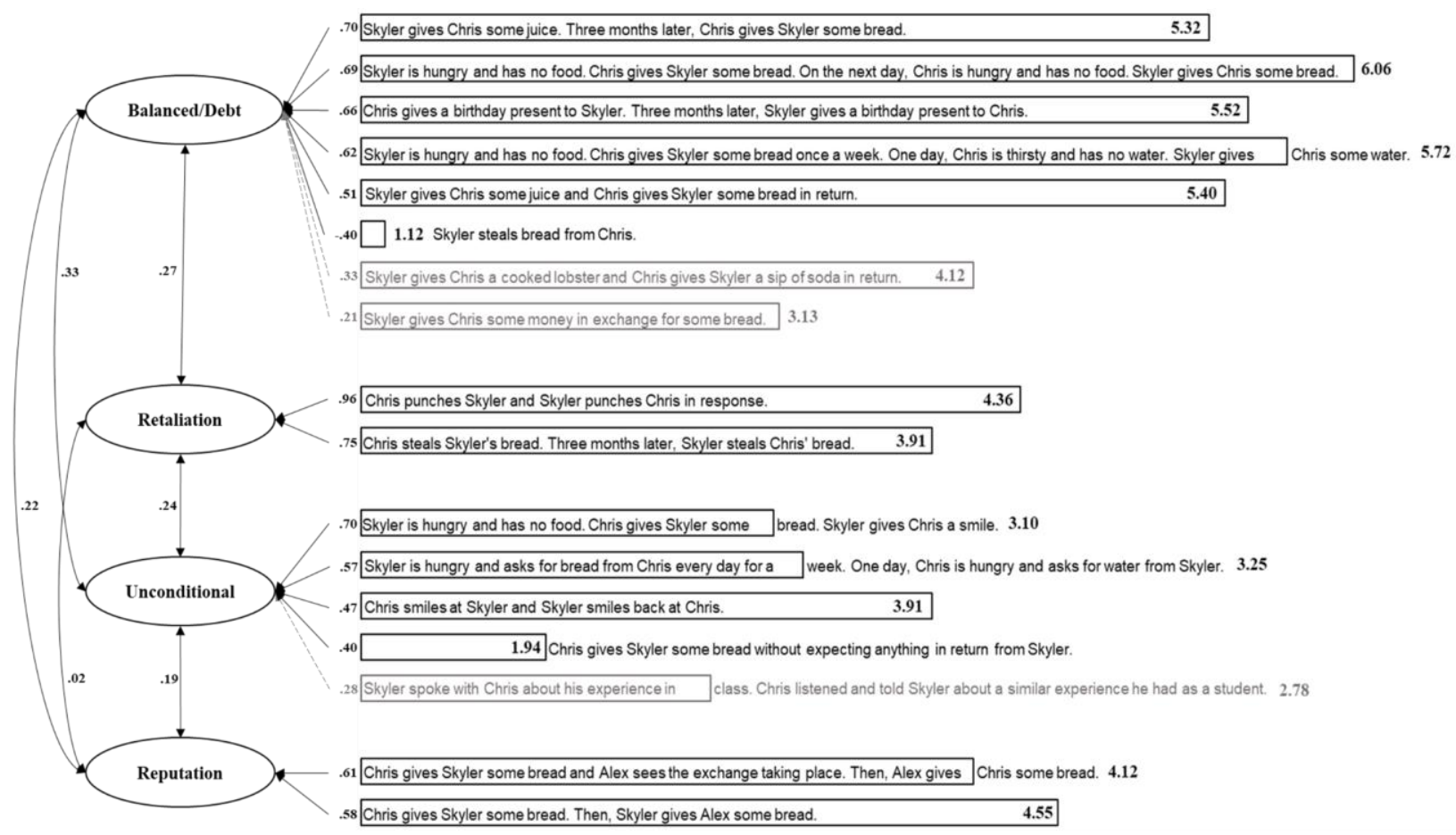

Note. The size of the bars represents mean scores regarding whether survey respondents agreed that the scenario is reciprocity $(1=$ definitely not reciprocity, $7=$ definitely reciprocity).

Solid lines indicate factor loadings $>=0.40$; dashed lines indicate factor loadings $<0.40$.

Responses clustered along three dimensions: Balanced Transfers, Conditional Punishment, and Unconditional Transfers.

Supplemental analyses show that, after removing participants who failed to report items assessing academic expertise, the three-factor solution (Table S9) yielded more interpretable results than did the four-factor solution (Table S10). Although both the three-factor and the fourfactor solution yielded similar Balanced/Debt-based, Retaliation, and Unconditional Transfers factors, the four-factor solution did not result in the fourth factor reflecting Reputation-Based Transfers. Instead, these two items (i.e., Chris gives Skyler some bread. Then, Skyler gives Alex some bread. And, Chris gives Skyler some bread and Alex sees the exchange taking 
place. Then, Alex gives Chris some bread.), loaded onto the Balanced/Debt-based transfers. These results suggest that some researchers may perceive that these scenarios were more akin to Balanced/Debt-based transfers than to Reputation-based transfers.

\subsubsection{Reciprocity ratings based on extracted factors (social scenarios)}

To explore whether researchers differed in the extent to which they considered the hypothetical scenarios to be reciprocity, we computed mean scores for the four factors extracted (see Figure 2). Paired-samples $t$-tests (Table 4) revealed that researchers considered Balanced/Debt-based Transfers scenarios to be more reciprocity than all other scenarios ( $d$ s $s=$ 0.30 to 1.47 ), and Retaliation ( $d=0.48)$ and Reputation-based Transfers scenarios $(d=0.64)$ to be more reciprocity than Unconditional Transfers. However, researchers did not rate Retaliation and Reputation-based Transfers scenarios differently $(p=0.55)$. A sensitivity analysis (pairedsamples $t, n=75, \alpha=0.05$, and $1-\beta=0.80$ ) shows that we were adequately powered to detect effects as small as $d=0.33$.

Supplemental analyses show similar results after removing participants who failed to report items assessing academic expertise (Table S11). We created composite scores for the Balanced/Debt-based, Retaliation, and Unconditional Transfers scenarios factors based on the three-factor solution shown in Table S9. Researchers rated Balanced/Debt-based Transfers scenarios to be more reciprocity than Retaliation $(d=0.48)$ and Unconditional Transfers scenarios $(d=1.67)$ and Retaliation to be more reciprocity than Unconditional Transfers scenarios $(d=0.52)$. 


\section{Table 4}

Paired-samples t-tests of reciprocity ratings (social scenarios factors)

\begin{tabular}{lcccccc}
\hline Comparison & $t(\mathrm{df})$ & $p$ & $M_{\text {diff }}$ & $95 \% \mathrm{Cl}$ & $d$ \\
\hline Balanced/Debt - Retaliation & $3.21(75)$ & 0.002 & 0.75 & 0.28 & 1.22 & 0.37 \\
Balanced/Debt - Unconditional & $12.85(75)$ & $<0.001$ & 1.82 & 1.54 & 2.10 & 1.47 \\
Balanced/Debt - Reputation & $2.63(75)$ & 0.01 & 0.56 & 0.14 & 0.98 & 0.30 \\
Retaliation - Unconditional & $4.18(75)$ & $<0.001$ & 1.07 & 0.56 & 1.58 & 0.48 \\
Retaliation - Reputation & $-0.60(75)$ & 0.55 & -0.19 & -0.82 & 0.44 & -0.07 \\
Reputation - Unconditional & $5.59(76)$ & $<0.001$ & 1.27 & 0.82 & 1.73 & 0.64 \\
\hline
\end{tabular}

\subsubsection{Reciprocity ratings based on extracted factors across fields (social scenarios)}

Because a test of homogeneity of variance showed that there were unequal variances across academic fields for ratings of Unconditional Transfers scenarios (Lavene's Statistic $=$ $4.84, p=0.002)$, we report the Welch's $F$ test for this factor. One-way ANOVAs showed that researchers across academic fields did not differ in their reciprocity ratings (Table S12) of Balanced/Debt-based Transfers scenarios $\left(F(4,50)=1.28, p=0.29, \eta^{2}=0.09\right)$, Reputationbased Transfers scenarios $\left(F(4,50)=0.63, p=0.64, \eta^{2}=0.05\right)$, or Unconditional Transfers scenarios (Welch's $\left.F(4,15.09)=1.08, p=0.39, \omega^{2}=0.03\right)$.

For Retaliation-based Transfers scenarios $\left(F(4,50)=2.61, p=0.046, \eta^{2}=0.17\right)$, posthoc pairwise comparisons with least squares difference suggest that biologists believed this factor to be less reciprocity than did psychologists $\left(M_{\text {diff }}=-1.84, p=0.01, \mathrm{Cl}_{95 \%}[-3.30,-0.38], d\right.$ $=0.91)$ and sociologists $\left(M_{\text {diff }}=-2.48, p=0.02, \mathrm{Cl}_{95 \%}[-4.60,-0.37], g=1.24\right)$. However, neither of these comparisons survived Bonferroni correction ( $p$ 's $>0.14$ ).

\subsubsection{Researcher agreement about the term reciprocity (social scenarios)}

To further explore the extent to which researchers agreed or disagreed that the 17 hypothetical scenarios were reciprocity, we ran Fleiss' Kappas for each scenario (1-3 = Not 
reciprocity, $4=$ Somewhat reciprocity, and 5-7 $=$ Is reciprocity). Researchers agreed that the following scenarios were reciprocity: Skyler is hungry and has no food. Chris gives Skyler some bread. On the next day, Chris is hungry and has no food. Skyler gives Chris some bread ( $k=$ $\left.0.78, \mathrm{Cl}_{95 \%}[0.75,0.81]\right) ;$ Skyler is hungry and has no food. Chris gives Skyler some bread once a week. One day, Chris is thirsty and has no water. Skyler gives Chris some water ( $k=0.76$, $\left.\mathrm{Cl}_{95 \%}[0.73,0.79]\right)$. In contrast, researchers agreed that Skyler steals bread from Chris was not reciprocity $\left(k=0.97, \mathrm{Cl}_{95 \%}[0.94,1.00]\right)$ (Table S13).

We found the same results after removing participants who failed to report items assessing academic expertise. Researchers $(n=67)$ agreed that these two scenarios are reciprocity: Skyler is hungry and has no food. Chris gives Skyler some bread. On the next day, Chris is hungry and has no food. Skyler gives Chris some bread $\left(k=0.80, \mathrm{Cl}_{95 \%}[0.77,0.83]\right)$; and Skyler is hungry and has no food. Chris gives Skyler some bread once a week. One day, Chris is thirsty and has no water. Skyler gives Chris some water $\left(k=0.78, \mathrm{Cl}_{95 \%}[0.74,0.81]\right)$. Researchers also agreed that Skyler steals bread from Chris was not reciprocity $\left(k=0.97, \mathrm{Cl}_{95 \%}\right.$ $[0.93,1.00])$. All other scenarios did not reach an acceptable level of agreement $(k$ 's $<0.66)$.

\subsubsection{Researcher disagreement about the term reciprocity (social scenarios)}

We looked at the open-ended responses of the social scenarios with the lowest rates of researcher agreement $(k$ s $<0.30, n=4)$ for clues of potential grounds of disagreement. The first of these scenarios (i.e., Chris gives Skyler some bread and Alex sees the exchange taking place. Then, Alex gives Chris some bread) loaded on the Reputation-based Transfers scenarios factor. We received 32 open-ended responses for this scenario, with the most common word used to describe this scenario being "indirect reciprocity" (71.9\% of responses). Although a majority of researchers who provided open-ended responses used the words "indirect reciprocity" to describe this scenario and rated the scenario on the higher end of the scale (i.e., $5-7$, where $7=$ is reciprocity), three researchers rated this scenario on the lowest end of the scale (i.e., 1 = is not reciprocity), and four researchers rated this scenario on the midpoint of the 
scale (i.e., 4). Potential grounds for disagreement included (1) whether researchers believed that "indirect reciprocity" should be considered reciprocity, (2) the nature of the relationship between the agents engaging in the transfer ("This could be some form of reciprocity depending on the specific nature of the relationships between these people"), and (3) lack of clarity (e.g., "can't tell without context").

The second of the scenarios with low researcher agreement (i.e., Skyler gives Chris a cooked lobster and Chris gives Skyler a sip of soda in return) did not load on any of the social scenarios factors. We received 20 open-ended responses for this scenario with two common themes, one surrounding words such as "unfair reciprocity," "free loading," "exploitation," and "negative reciprocity" ( $25 \%$ of responses), and the second surrounding words such as "exchange but not of similar kind," "weak reciprocity," "mixed-kind reciprocal altruism," "reciprocal exchange," and "direct reciprocity" (25\% of responses). Potential grounds for disagreement included (1) whether researchers viewed the scenario as exploitation, as some kind of reciprocity, or as some other form of cooperative transfer (e.g., one researcher used the word "mutualism"); (2) whether any intent was involved (i.e., "words like 'in return' assume something about intent and conditionality, which makes all the difference for reciprocity"); (3) the value of the items being transferred (e.g., "It depends on the value of each item to S \& C"); and (4) lack of clarity.

The third scenario with low agreement (i.e., Chris smiles at Skyler and Skyler smiles back at Chris) loaded on the Unconditional Transfers scenarios factor. We received 18 openended responses for this scenario. Researchers used words such as "signal/signaling" ( $11 \%$ of responses), "friendship/friendliness" (11\% of responses), and "direct reciprocity/direct positive reciprocity/positive reciprocity" (16\% of responses). Potential grounds for disagreement included (1) whether researchers viewed the scenario as a friendly interaction, as a signal, as some kind of reciprocity, or as something else (e.g., "behavioral mimicry", "...[a] prosocial act"); (2) whether any intention was involved (i.e., "The intention matters. Did Skyler smile back because of 
obligation (reciprocity) or for some other reason (not reciprocity"); and (3) whether only one or both agents are engaging in reciprocity (i.e., "At this stage, only Skyler is reciprocating, but Chris may reciprocate later with another smile").

The fourth scenario with low researcher agreement (i.e., Chris punches Skyler and Skyler punches Chris in response) loaded on the Retaliation scenarios factor. We received 23 open-ended responses for this scenario, with four common themes emerging from the words "negative reciprocity" ( $17.4 \%$ of responses), "tit for tat" (13\% of responses), from words such as "revenge," "retaliation," and "punishment" (17.4\% of responses), and from words such as "fight/fighting," "aggression," "quarrel," and "agonistic interaction" (26.1\% of responses). Potential grounds for disagreement included whether the scenario was some kind of reciprocity, retaliatory behavior, or mere aggression.

\subsection{Differences and similarities between definitions and social scenarios of reciprocity}

As an additional test of our results, we ran exploratory factor analyses with both the scholarly definitions of reciprocity and the social scenarios. A six-factor solution accounting for $48 \%$ of the variance yielded the most interpretable results $\left(\chi^{2}(814)=869.77, p<0.08, \mathrm{TLI}=\right.$ $\left.0.90, \mathrm{RMSR}=0.06, \mathrm{RMSEA}=0.03, \mathrm{Cl}_{90 \%}[0.00,0.05]\right)($ Table S14). This solution resulted in factors similar to those extracted from the previous analyses.

The two scenarios akin to reputation-based transfers (e.g., Chris gives Skyler some bread and Alex sees the exchange taking place. Then, Alex gives Chris some bread) loaded with scholarly definitions (e.g., Reciprocal altruisma: acting altruistically towards another who has already acted altruistically) on a Reputation-based Transfers factor. Three scenarios akin to unconditional transfers (e.g., Skyler is hungry and has no food. Chris gives Skyler some bread. Skyler gives Chris a smile) loaded with the scholarly definitions (e.g., Generalized reciprocity l: Non-conditional sharing and giving of assistance) on an Unconditional Transfers factor. Another factor was composed of scholarly definitions reflecting Debt-based Transfers (e.g., Calculated 
reciprocity: When individuals keep track of the benefits they exchange with particular partners, which helps them decide to whom to return favors).

The two retaliation scenarios (e.g., Chris steals Skyler's bread. Three months later, Skyler steals Chris' bread) loaded with Negative reciprocity II (An action that has a negative effect upon someone else is repaid with an action that has approximately equal negative effect upon another) on a Retaliation factor. Interestingly, Tit-for-Tat (When individuals cooperate if the other party cooperates, and defect if the other party defects) also loaded the strongest on this Retaliation factor (factor loading $=0.38$ ), suggesting that researchers emphasized the defection aspect of this definition, and in part explaining why Tit-for-Tat did not load onto any of the other factors extracted from the scholarly definitions of reciprocity. Accordingly, researchers used the words "tit for tat" to describe the scenarios that loaded on this Retaliation factor.

The main difference between our previous analyses and the current analysis is that the scholarly definitions and social scenarios that loaded on the Balanced Transfers factors did not load onto a single factor. Instead, they made up two separate factors, one that included mostly (only one scenario loaded on this factor) scholarly definitions (e.g., Heteromorphic reciprocity: Exchange of things that are concretely different but of equal value), and one that included only social scenarios (e.g., Skyler gives Chris some juice. Three months later, Chris gives Skyler some bread). When we looked at researchers' open-ended responses to the items that made up these factors, the difference appears to stem from two things: attributions about the nature of the relationship between the agents engaging in these transfers. And two, ambiguities about the value placed on the items being transferred by the agents.

Researchers used words such as "trade," "deal," "bargaining," "credit," and "market transaction" to describe the scholarly definitions, suggesting that researchers saw these transfers as stemming from market-like transactions. This is further corroborated by the fact that the scenario Skyler gives Chris some money in exchange for some bread loaded on this first factor. Although researchers also used words such as "economic exchange" to describe the 
social scenarios factor, other researchers said that whether a scenario should be considered reciprocity depends on the "communal relationship and what's happened in the interim."

We ran a paired samples $t$-test comparing these two factors and found that researchers believed that the Balanced/Market-based transfers factor $(M=3.99, S D=1.52)$ was less reciprocity than the Balanced/Relationship-based scenarios factor $(M=5.07, S D=1.09, t(68)=$ $\left.-6.59, p<0.001, M_{\text {diff }}=-1.08, \mathrm{Cl}_{95 \%}[-1.41,-0.75], d=-0.79\right)$. We also ran One-Way ANOVAs looking for differences in reciprocity ratings for these two factors across academic fields. Researchers did not differ in their ratings of reciprocity for the Balanced/Relationship-based scenarios factor $\left(F(4,50)=1.31, p=0.28, \eta^{2}=0.09\right)$. However, researchers did differ in their ratings of the Balanced/Market-based transfers factor $\left(F(4,50)=3.02, p=0.02, \eta^{2}=0.19\right)$. Post-hoc comparisons with least-squares differences show that economists $(M=2.87, S D=$ 1.17) rated Balanced/Market-based transfers as less reciprocity than did biologists $\left(M_{\text {diff }}=-1.67\right.$, $\left.p=0.005, \mathrm{Cl}_{95 \%}[-2.83,-0.52], g=1.20\right)$, psychologists $\left(M_{\text {dift }}=-1.77, p=0.003, \mathrm{Cl}_{95 \%[}[-2.93,-\right.$ 0.62 ], $g=1.50)$, and sociologists $\left(M_{\text {diff }}=-1.73, p=0.03\right.$, Cl95\%[-3.34, -0.12$\left.], g=1.24\right)$. However, only the comparison between economists and psychologists survived Bonferroni correction ( $p=$ 0.03).

\subsection{How do researchers respond to the question "what is reciprocity?"}

In the last section of the survey, we asked experts to respond to the question what is reciprocity? Some individuals responded with relatively concise definitions, others discussed themes relevant to the concept of reciprocity, and yet others expressed concerns with definitions of reciprocity (full responses available in SI S2). All individuals included in these qualitative responses gave their permission to have their comments included in a publication at the time of taking the survey. We also looked at the open-ended responses participants provided for the scholarly definitions to corroborate the qualitative responses.

\subsubsection{Definitions}


Several of our respondents provided definitions of reciprocity in the free response. We have excerpted these definitions from the responses, some of which we have edited for length.

Bovet, Dalila: "when the gift of some food, or another favor, increases the probability for the donor to receive the same thing, or something else, from the receiver"

Carter, Gerald: "when an organism makes cooperative investments that are in some way contingent on the experience (or memory) of cooperative returns from the recipient"

Fehr, Ernst: "Reciprocal strategies in repeated games [...]. A social norm [...] to respond to a favour [...] or an insult [...]. [A preference] to respond to kind acts with kind acts and to unkind acts with unkind acts."

Fischbacher, Urs: "be good to good people [...] and be bad to bad people [...] reciprocity can be based on the action, and it can be based on the preferences."

Gaechter, Simon: "a pattern of behavior that responds to a beneficial act one has received with an act that is beneficial for the person (or group of people) whose beneficial act one has enjoyed in the first place."

Kenny, Dave: "a partner effect in the sequential [Actor-Partner Interdependence Model]."

Lister, Andrew: "a non-instrumental tendency to respond in kind."

Mesterton-Gibbons, Mike: "one good turn deserves another, and one bad turn deserves another too" [from his textbook, Introduction to Game-Theoretic Modelling (Mesterton-Gibbons, 2019)].

Noguera, Jose A.: "conditional cooperation/punishment [...] conditional to previous or expected cooperation/punishment by the relevant subjects or type of subjects."

Sabourin, Eric: "relationship motivated by an interest in the other by the production of social ties."

Taborsky, Michael: "an apparently cooperative trait or behaviour that benefits a receiver of the act at immediate costs to the actor [and] increases the probability to receive benefits in return, from the same or different partners." 


\subsubsection{Themes}

\subsubsection{Is reciprocity conditional?}

In the qualitative responses, experts mentioned several themes including the idea that reciprocity is characterized by "conditionality" (Noguera, Fischbacher, Fehr, MestertonGibbons, Carter, Lister). When looking at the open-ended responses of the scholarly definitions, for example, two researchers wrote that "If it's non-conditional, then it's not reciprocity." However, we can also see that researchers emphasized different types of conditions. Out of all of the open-ended responses (i.e., 548 observations provided by $n=48$ participants), 39 responses $(7.1 \%$ of all observations) provided by $13(15.3 \%)$ participants dealt with the issue of conditionality. The most common conditions for a definition to be considered reciprocity included that: (1) a transfer is not reciprocity if there is a formal contract/agreement or if it involves goods being purchased ( $\left.n_{\text {participants }}=4\right)$; (2) a transfer is reciprocity depending on the relationship (e.g., if the recipient is kin; $\left.n_{\text {participants }}=4\right)$; (3) a transfer is reciprocity only if agents are engaging in an investment or get a return ( $\left.n_{\text {participants }}=3\right)$; (4) a transfer is reciprocity if it is positive/has value ( $\left.n_{\text {participants }}=2\right)$; (5) a transfer is reciprocity if it is dyadic $\left(n_{\text {participants }}=2\right)$; and (6) a transfer is reciprocity if the agents are engaging in strategic behavior or are keeping score $\left(n_{\text {participants }}=2\right)$. In contrast to this last condition, (7) one researcher wrote that "keeping track is not reciprocity;" and (8) another researcher argued that a transfer is not reciprocity if agents "are giving to show off, in that case it is signaling."

\subsubsection{Is reciprocity intentional?}

Another theme mentioned in the qualitative responses is that the concept of reciprocity should include not just behavior but also preferences for engaging in reciprocal behaviors (Fehr and Fischbacher), and one respondent said that "intent" was critical to concepts of reciprocity as applied to humans (Chalub). Echoing Fehr and Chalub, Schino wrote that in reciprocity "one tries to influence the other by incentivizing or punishing," and two other researchers provided six open-ended responses ( $1.1 \%$ of all observations) of the scholarly definitions indicating that the 
concept of reciprocity depends on the intentions (e.g., "if [the] intent is to reward other person's altruism"), and preferences of the agents (e.g., "expectation that other will have reciprocal preferences").

\subsubsection{Is reciprocity best defined according to the psychology of the giver or the transfer's impact on the receiver?}

Another theme that emerged from the qualitative responses is the question of whether the hallmarks of reciprocity are to be found in the psychology of the giver or in the impact that a transfer has on receivers. One respondent noted that "Reciprocity is [...] a proximate (i.e., mechanistic) concept implying decision rules evolved through certain cost/benefit relationships" (Taborsky). In parallel to Taborsky, one researcher wrote "...I would ask WHY is the person being altruistic to others (the conscious proximate reason). The answer might be because of [an] obligation to give back (reciprocity) or for some other reason (not reciprocity)".

In contrast to Taborsky, Noë suggested that the focus of definitions of reciprocity should be on the actual transfer [and fitness impact] of benefits from one individual to another and "the actions of agents [like] ' $X$ invests in Y'”. Echoing Noë, another researcher wrote that "[reciprocity] must be judged only from the outcome (not the intention)."

\subsubsection{Concerns}

The experts who responded to our survey voiced several concerns about the use and definitions of reciprocity terms. Pointing to the issue of mixing up proximate with ultimate-level explanations, Gaechter noted that "even people with no pro-social motivations whatsoever can behave reciprocally if it furthers their (long-run) strategic incentives, including incentives for being in good standing..." According to him, this leads to situations where "reciprocity can be confounded with purely egoistic, transactional incentives."

Researchers also voiced concerns that existing definitions are not adequate. One respondent noted that "the formulation [of existing definitions of reciprocity] is rather sloppy" (Fischbacher). Echoing Fischbacher, 10 (11.7\%) researchers provided 11 open-ended 
responses ( $2 \%$ of observations) for the scholarly definitions voicing similar concerns. The most common (i.e., 7) of the responses dealt with the use of the word "altruism" within definitions of reciprocity, with researchers indicating that transfers that involve a back-and-forth of transfers or expectations of repayment should not be considered altruistic (e.g., "...Altruism by definition implies no return benefits to the altruist").

A second researcher who voiced concerns about the adequacy of existing definitions noted that "indirect reciprocity means different things to different people" (Mesterton-Gibbons). Indeed, 20 (23.5\%) researchers provided 52 open-ended responses (9.5\% of observations) spanning seven different scholarly definitions where they used the words "indirect reciprocity" to describe a scholarly definition. Not only did different researchers use "indirect reciprocity" to describe different scholarly definitions, but 11 of these researchers used the words "indirect reciprocity" on more than one occasion to describe different scholarly definitions.

Finally, another respondent mentioned the challenges of finding the right level of specificity for definitions of reciprocity. He noted that defining reciprocity too generally leads to a situation where "all enforced forms of mutual benefits are a form of reciprocity" while defining it so narrowly that it requires "cognitively calculated cooperative investments" is "a distortion of the original concept" (Carter).

\section{Discussion}

\subsection{What is reciprocity?}

\subsubsection{Reciprocity is (perceived to be) characterized by balance, debt, and reputation}

We explored the extent to which researchers deem various types of cooperation to be reciprocity, including thirty definitions taken from the scholarly literature and seventeen hypothetical social scenarios. Employing exploratory factor analyses, we discovered that the various types of reciprocity could be distilled into four types of transfers: (1) Balanced Transfers, which include transfers that are of equal or equivalent value, including both instances in which 
items are transferred in-the-moment, or with some delay; (2) Reputation-based Transfers, which include types of transfers where individuals give to others who have given in the past and receive from others if they have given in the past. These included transfers between dyads, a third person, or from other individuals within the network. 3) Debt-based Transfers, which include types of transfers where individuals keep track of, and expect repayment for, what they give to others, including transfers that occur between dyads, or among members of a network. 4) Unconditional Transfers, which include types of transfers that do not revolve around concepts of debt or account keeping and that may occur between dyads or among members of a network.

Reciprocity experts appear to have some level of consensus, such as agreeing that the term reciprocity is both useful and necessary. Moreover, researchers across academic fields provided similar ratings of reciprocity for the Balanced, Reputation-based, and Debt-based Transfers factors of the scholarly definitions, indicating that researchers across academic fields agree on the overall degree to which these types of transfers are representative of the term reciprocity. However, mean scores for the Balanced, Reputation-based, and Debt-based factors fell within the mid-point of the scale (i.e., $1=$ is not reciprocity, 7 = is reciprocity), indicating that neither of these types of transfers was strongly considered to be reciprocity.

\subsubsection{Reciprocity is (perceived to be) characterized by informal transfers}

We observed similar patterns for the hypothetical social scenarios, with researchers across academic fields rating the Balanced/Debt-based, Retaliation, and Reputation-based Transfer scenarios on the mid-point of the scale, showing some level of consensus regarding the degree to which these transfers are considered reciprocity. However, unlike the scholarly definitions, researchers rated Balanced/Debt-based Transfer scenarios to be more reciprocity than Retaliation and Reputation-based Transfer scenarios.

Further analyses indicated that researchers believe that balanced transfers that occur outside of formal transactions (e.g., contracts, institutions, markets), are considered more reciprocity than those that occur within formal transactions. This was supported by four 
observations. First, the Balanced/Relationship-based scenarios received the highest rating of all factors. Second, researchers rated the Balanced/Relationship-based scenarios to be more reciprocity than the Balanced/Market-based Transfers $(d=0.79)$. Third, four researchers $(4.7 \%)$ provided open-ended responses in which they explicitly stated that a transfer is not reciprocity if it occurs within a formal agreement (e.g., "[is reciprocity] On [the] condition that there is no official agreement or obligation"). And, fourth, a majority of researchers (89-90\%) agreed that two of the Balanced/Relationship-based scenarios were reciprocity (e.g., Skyler is hungry and has no food. Chris gives Skyler some bread. On the next day, Chris is hungry and has no food. Skyler gives Chris some bread).

\subsubsection{Reciprocity is not (perceived to be) unconditional}

The clearest consensus we observed in this study was with regard to the extent to which experts believe that reciprocity is conditional. This conclusion was supported by three observations. First, the Unconditonal Transfers factors received the lowest rating of reciprocity compared to all other factors on both the scholarly definitions and the social scenarios ( $d$ 's $=$ 0.48 to 1.70 ), and researchers did not differ in their ratings of Unconditional Transfers across disciplines. The definitions that loaded on Unconditional Transfers and that should not be considered reciprocity according to experts in this survey were Generalized reciprocity I, Network reciprocity, Negative Reciprocity I, and Strong reciprocity II.

Second, most researchers (90-96\%) agreed that Negative Reciprocity I (acquisition of benefit without intent to repay), and Strong Reciprocity II (non-conditional altruism and punishment favored by group selection) were not truly reciprocity. And, third, $13(15.3 \%)$ researchers explicitly stated that a transfer is reciprocity only if it is accompanied by some type of condition ( $7.1 \%$ of open-ended responses), such as the condition that transfers involve a return to the giver. Similarly, an additional six researchers $(7 \%)$ wrote that reciprocity includes some kind of conditionality in their qualitative responses to the question What is reciprocity? 


\subsection{What do researchers disagree about the most regarding the term reciprocity?}

Researchers provided open-ended responses to the question What word would you use to describe this [definition/scenario]?. We searched within the scholarly definitions and social scenarios with the lowest rates of agreement (Table 5). We also looked through all open-ended and qualitative responses to the question What is reciprocity? to see how common these points of disagreement are. In addition to researchers using the same definition to describe multiple scholarly definitions (most notably "indirect reciprocity"), we identified six potential grounds for disagreement: (1) Preferences/Intentionality: researchers (5.9\%, including Fehr, Chalub, and Schino) indicated that transfers were reciprocity if agents had the intention to reward a giver or incentivize a receiver to give back. (2) Value of the transfer: researchers (8.2\%, including Fischbacher, Fehr, Noguera, Mesterton-Gibbons, Schino, Carter, and Gaechter) stated that reciprocity involved both negatively and positively valued transfers. However, two $(2.3 \%)$ researchers stated that a transfer was reciprocity only if it had a positive value/utility.

(3) Expectations of return/account keeping: researchers (12.9\%, including Noguera, Mesterton-Gibbons, Carter, Gaechter, Fehr, Noë) stated that reciprocity involved expectations of return, keeping score, and strategic behavior. In contrast, one researcher stated that a transfer was not reciprocity if it involved "keeping track," and Lister stated that reciprocity is "non-instrumental." (4) Formal transactions: researchers (4.7\%) indicated that a transfer was reciprocity only if it did not involve a formal/market transaction. (5) Type of relationship: researchers (5.9\%) stated that a transfer was reciprocity depending on the relationship between/among the agents. Two researchers, including Mesterton-Gibbons, stated that transfers that occurred within close or mutualistic relationships were not reciprocity, while another researcher stated that a transfer was reciprocity if the recipient was kin. (6) Costliness: researchers (3.5\%, including Taborsky, and Mesterton-Gibbons) stated that reciprocity involved a cost. However, another researcher stated that reciprocity does not involve "costs or negative actions." 


\section{Table 5}

\section{Open-ended responses showing potential grounds for disagreement about the term reciprocity}

\begin{tabular}{|c|c|c|c|}
\hline Definition/scenario (Factor) & $n$ & Disagreement (Obs.) & Sample response \\
\hline \multirow{4}{*}{$\begin{array}{l}\text { Balanced Reciprocity: } \\
\text { Transfers of equal value } \\
\text { (Balanced) }\end{array}$} & \multirow[t]{4}{*}{17} & Agent's intent (1) & $\begin{array}{l}\text { "depends on intent. This could be rewarding good behavior or simply a mutually } \\
\text { beneficial transaction" }\end{array}$ \\
\hline & & Value of transfer (1) & "If the value is positive" \\
\hline & & Number of agents (1) & "between a pair of actors? Then yes [it is reciprocity]" \\
\hline & & Expectation of return (1) & "If part of a give and take" \\
\hline $\begin{array}{l}\text { Delayed Reciprocity: Payment } \\
\text { with delay between initial transfer } \\
\text { and repayment (Balanced) }\end{array}$ & 14 & Formal transaction (2) & "depends on whether this is in an instutionlized setting with contract enforcement etc" \\
\hline \multirow{3}{*}{$\begin{array}{l}\text { Homeomorphic Reciprocity: } \\
\text { Exchange of things that are the } \\
\text { same (Balanced) }\end{array}$} & \multirow[t]{3}{*}{20} & Formal transaction (4) & "exchange of cash for goods at a store is not a good example of reciprocity" \\
\hline & & Agent's intent (1) & "depends on intent of the parties involved" \\
\hline & & Value of transfer (1) & "if the things are useful" \\
\hline \multirow{3}{*}{$\begin{array}{l}\text { Heteromorphic Reciprocity: } \\
\text { Exchange of things that are } \\
\text { concretely different but of equal } \\
\text { value (Balanced) }\end{array}$} & \multirow[t]{3}{*}{20} & Formal transaction (2) & $\begin{array}{l}\text { "depends on what the things are and how they are exchanged. cash for goods at a } \\
\text { store doesn't count" }\end{array}$ \\
\hline & & Agent's intent (1) & $\begin{array}{l}\text { "This sounds like a simple exchange. No one gave first with the hope of making the } \\
\text { other feel more obligated to give back in the future" }\end{array}$ \\
\hline & & Lack of risk (1) & $\begin{array}{l}\text { "In the reciprocity world, there needs to be a risk that the other person might not } \\
\text { reciprocate" }\end{array}$ \\
\hline $\begin{array}{l}\text { Reciprocity II: A situation where } \\
\text { today's giving will be } \\
\text { recompensed by tomorrow's } \\
\text { taking (Balanced) }\end{array}$ & 12 & Expectation of return (3) & $\begin{array}{l}\text { "...For reciprocity, this should be 'A situation where today's giving will be } \\
\text { recompensed by tomorrow's RECEIVING”" }\end{array}$ \\
\hline $\begin{array}{l}\text { Scenario 2: Skyler gives Chris a } \\
\text { cooked lobster and Chris gives }\end{array}$ & 20 & Value of transfer (2) & "It depends on the value of each item to S \& C" \\
\hline $\begin{array}{l}\text { Skyler a sip of soda in return } \\
\text { (Balanced/Relationship) }\end{array}$ & & Agent's intent (1) & $\begin{array}{l}\text { "words like "in return" assume something about intent and conditionality, which makes } \\
\text { all the difference for reciprocity" }\end{array}$ \\
\hline $\begin{array}{l}\text { Weak } \\
\text { Reciprocity II: A requirement that }\end{array}$ & 15 & $\begin{array}{l}\text { Lack of risk/formal transaction } \\
\text { (1) }\end{array}$ & $\begin{array}{l}\text { "This is not reciprocity. The requirement makes this a contract, where there is no real } \\
\text { risk that a person won't give back" }\end{array}$ \\
\hline
\end{tabular}




\begin{tabular}{|c|c|c|c|}
\hline \multicolumn{2}{|l|}{ givers receive a benefit (Debt) } & Expectation of return (1) & "This is reciprocity if the giver receives its benefit from the original receiver" \\
\hline $\begin{array}{l}\text { Scenario 9: Chris gives Skyler } \\
\text { some bread and Alex sees the } \\
\text { exchange taking place. Then, } \\
\text { Alex gives Chris some bread } \\
\text { (Reputation) }\end{array}$ & 32 & Agent's relationship (1) & $\begin{array}{l}\text { "This could be some form of reciprocity depending on the specific nature of the } \\
\text { relationships between these people" }\end{array}$ \\
\hline $\begin{array}{l}\text { Scenario 11: Chris punches } \\
\text { Skyler and Skyler punches Chris } \\
\text { in response (Retaliation) }\end{array}$ & 23 & Interpretation (23) & $\begin{array}{l}\text { Researchers used words such as "negative reciprocity" (17.4\%), "tit for tat" (13\%), } \\
\text { "retaliation" (17.4\%), and "aggression" }(26.1 \%)\end{array}$ \\
\hline \multirow{2}{*}{$\begin{array}{l}\text { Scenario 6: Chris smiles at } \\
\text { Skyler and Skyler smiles back at } \\
\text { Chris (Unconditional) }\end{array}$} & 18 & Agent's intent (2) & $\begin{array}{l}\text { "The intention matters. Did Skyler smile back because of obligation (reciprocity) or for } \\
\text { some other reason (not reciprocity)" }\end{array}$ \\
\hline & & Expectation of return (1) & $\begin{array}{l}\text { "At this stage, only Skyler is reciprocating, but Chris may reciprocate later with } \\
\text { another smile" }\end{array}$ \\
\hline $\begin{array}{l}\text { Symmetry-based Reciprocity: } \\
\text { When mutual affection between } \\
\text { two parties prompts similar } \\
\text { behavior in both directions } \\
\text { without the need to keep track of } \\
\text { give-and-take, so long as the } \\
\text { relationship remains satisfactory }\end{array}$ & 17 & $\begin{array}{l}\text { Interpretation/agent's } \\
\text { relationship ( } 7)\end{array}$ & $\begin{array}{l}\text { Researchers who used words ( } 41.2 \%) \text { that described close or communal } \\
\text { relationships (e.g., "friendship," "commitment," and "communal relationship") gave } \\
\text { both low and high ratings of reciprocity for this definition }\end{array}$ \\
\hline \multirow{2}{*}{$\begin{array}{l}\text { Negative Reciprocity II: An action } \\
\text { that has a negative effect upon } \\
\text { someone else is repaid with an } \\
\text { action that has approximately } \\
\text { equal negative effect upon } \\
\text { another (Retaliation) }\end{array}$} & 26 & Costliness (2) & $\begin{array}{l}\text { "[it is reciprocity] If it is costly" } \\
\text { "I do not believe that reciprocity describes relationship costs or negative actions" }\end{array}$ \\
\hline & & Expectation of return (1) & "[ls reciprocity] But only if 'another' is the original actor whom 'someone else' repays" \\
\hline
\end{tabular}

Note. The table shows the definitions and social scenarios that received the lowest inter-researcher agreement $(k s<0.30)$ to the question: Is this reciprocity? $(1=$ definitely not reciprocity, $7=$ definitely reciprocity $) . n=$ the number of participants that provided an open-ended response to the question What word would you use to describe this [definition/scenario]?. Obs. = the number of openended responses provided for a given definition/scenario. The percentages reflect the proportion of observations that correspond to a given type of response. 


\subsection{Is it necessary to use new terms to describe the 'types of reciprocity'?}

\subsection{1. "Why I prefer defining verbs rather than nouns" (Noë)}

We suggest that, based on the expert responses to our survey, a new terminology of 'balanced transfers,' reputation-based transfers,' 'debt-based transfers,' and 'unconditional transfers' should be considered for talking about categories, or dimensions, of reciprocity. In any situation when new terms are being proposed, it is important to justify why existing terms cannot simply be used. We suggest that using the term 'transfer' offers greater clarity than terms such as reciprocity or cooperation. Here, we echo Noë in "defining verbs rather than nouns," and in the "need [for] definitions of the visible outcomes of these [reciprocal] strategies: the actions of agents." Although the term reciprocity has a long history, our results clearly indicate that this term often means different things to different researchers. A transfer focuses on the action of agents. And, unlike reciprocity, the term transfer does not automatically imply that the action is mutual or conditional (e.g., an expectation of return). On this point, the terms loading on the 'unconditional transfers' dimension (i.e., Generalized Reciprocity I, Network Reciprocity, Negative Reciprocity I, and Strong Reciprocity II) were consistently rated as not 'reciprocity,' making the term 'transfers' more appropriate. Rather than some type of reciprocity, some unconditional transfers may better fit the types of cooperation that fall under risk-pooling, such as instances in which individuals make decisions about helping based on the recipient's need (Cronk et al., 2019; Cronk \& Aktipis, 2021), as opposed to dimensions relating to balance or debt.

Moreover, unlike the term cooperation, which implies mutually beneficial actions, a transfer is agnostic towards the effect on the recipient. As Noë argues: “...An investment [or transfer] can be defined ... independent of the way in which it is embedded in the temporary structure of actions: before, during or after an action by the receiver of the investment, but also in the absence of any action of the receiver. Correctly defined, it remains one and the same action independent of context and thus a genuine target of selection." 


\subsubsection{Reducing the number of dimensions used to define a transfer}

We also echo one of our kind reviewers in recognizing that individuals may engage in transfers that are simultaneously balanced, heteromorphic, delayed, indirect, and calculated (or many other possible combinations). In the case of the framework we suggest here, the main reason to consider these new terms is that no commonly used existing terms capture the variation within the factors that emerged from factor analysis of the expert responses. In adopting these terms, we can provide specific qualifiers to a transfer while at the same time reducing the possible number of dimensions that describe a transfer based on whether, or the extent to which, they are balanced, debt-based, reputation-based, or unconditional.

We also recognize that these four dimensions do not specify the effect of the action on the recipient. Whether a transfer provides a benefit to or imposes a cost on its recipient must still be clearly identified by researchers studying any particular transfer. On this point, three researchers (3.5\%) indicated that a transfer was only reciprocity if it had a positive value/did not involve negative actions, while another indicated that both negative and positive actions were reciprocity, making the term 'transfer' more appropriate than reciprocity.

In addition, a reviewer pointed out that some definitions we included in our study focus on the proximate mechanisms involved (e.g., motivations and decision rules, as in attitudinal and calculated reciprocity), while others are more about the ultimate level of explanation because they include information about the selection pressures thought to have favored the behavior. For example, the term "risk reduction reciprocity" includes within it an assertion about the selection pressures that would have favored the behavior in question among our ancestors. In contrast, while the terms we are proposing (balanced, debt-based, reputation-based, and unconditional transfers) do include information about the proximate mechanisms thought to underlie a particular transfer (e.g., to create a debt or to improve the donor's reputation), they do not by themselves imply any particular set of selection pressures that might have been responsible for their evolution. For example, the types of transfers that occur among hunter- 
gatherers in systems of central place provisioning (Berbesque et al., 2016; Cashdan, 1989; Isaac, 1983; Marlowe, 2005) were likely to have been favored by selection due to their value in pooling risk (Bliege Bird et al., 2000; Cronk \& Aktipis, 2021); and might be motivated at the proximate level by concerns about a recipient's need or concerns about the donor's reputation.

Some readers might wonder why we did not use the language of direct, indirect, and generalized reciprocity. In their qualitative responses, two experts (Fischbacher and Taborsky) described direct, indirect, and generalized reciprocity as the three types of reciprocity. Indeed, Direct reciprocity loads onto debt-based transfers $(0.80)$, Indirect reciprocity (0.53) and Generalized reciprocity II (0.73) load onto reputation-based transfers, and Generalized reciprocity I loads onto unconditional transfers $(0.69)$. This suggests that these dimensions of reciprocity do map reasonably well onto this framework. However, in our factor analysis, many other types of transfers are also loaded with each of these broader factors, types of transfers that are not captured by direct, indirect, and generalized reciprocity definitions.

\subsection{Limitations}

While our sample size was reasonable overall, samples within academic disciplines were small. In addition, open-ended responses to the scholarly definitions were labeled as optional. This led to only receiving $21.5 \%$ open-ended responses (out of a total possible of 2550 responses) from $56.5 \%$ of participants in our sample. This makes it hard to really look at consensus among researchers within disciplines, and among researchers across disciplines. Thus, with the exception of unconditional transfers not being considered reciprocity, findings regarding consensus among experts (or lack thereof) should be treated as suggestive, rather than conclusive. A second limitation to note is that findings regarding the four factors underlying the scenarios could be partly an artifact of the types or numbers of scenarios included in our survey. In addition, our survey included only 17 scenarios. Including a greater variety of scenarios could have yielded a different underlying structure. A third limitation to note is that we looked only at reciprocity terms and not at a broader range of cooperation terms or cooperative 
scenarios (e.g., partner choice/positive assortment, mutualism, spiteful cooperation). Including cooperation terms not captured by the scholarly definitions could have also resulted in a different underlying structure.

A fourth limitation was the lack of diversity in our sample. Respondents were predominantly male and from Western societies, and, because we did not ask about other dimensions of diversity, it is possible that our responses are limited in other dimensions as well. Also, we limited our search for participants to papers from authors that included the words "cooperation" or "reciprocity" in the title, failing to include "reciprocal" in our search. This means that we may have missed other experts who may be working on similar topics but using other words or terms such as "reciprocal altruism." Lastly, although the scholarly definitions included both ultimate-level (e.g., risk-reduction) and proximate-level explanations for behavior (e.g., calculated reciprocity), the definitions shown to participants did not provide information about the level of analysis. As a result, we are not able to test whether researchers agree or disagree that a transfer is reciprocity depending on the level of analysis.

\subsection{Future directions}

\subsubsection{Addressing potential grounds for disagreement}

Using the qualitative and open-ended responses experts provided, we identified six potential grounds for disagreement regarding whether a transfer is considered reciprocity: the intention/preferences of agents engaging in transfers, value (or effect) a transfer has on the recipient, agents' expectations of return/account keeping, formal/market-based vs. informal/relationship-based transfers, the type of relationship between agents, and the costliness of a transfer. Researchers may consider investigating these dimensions to reduce disagreements regarding whether these dimensions are characteristic of the term reciprocity.

\subsubsection{Extending to broader cooperation terms and specifying the level of analysis}

In addition to reciprocity terms, another avenue for future research could be to survey cooperation experts about a wider range of cooperative acts and scenarios such as (but not 
limited to) positive assortment, partner choice, mutualism, kin selection, fitness interdependence, spiteful cooperation, need-based transfers, and cultural evolution. In addition, it would behoove researchers to clearly define terms with regard to the unit of selection (e.g., genes, individuals, group/network) and to the level of analysis (i.e., whether it is proximate or ultimate) to which it is intended to apply. Such studies may help researchers reach a greater consensus regarding the types, or dimensions, that constitute these various cooperative strategies and supporting proximate mechanisms.

\subsubsection{Interdisciplinary collaboration}

Our results suggested that economists rated Balanced/Market-based transfers as less reciprocity than did biologists $(g=1.20)$, sociologists $(g=1.24)$, and psychologists $(g=1.50)$. However, only the comparison between economists and psychologists survived Bonferroni correction. Economists also rated Debt-based Transfers to be less reciprocity than did psychologists $(g=0.95)$, and sociologists $(g=1.91)$, but only the comparison between economists and sociologists survived Bonferroni correction.

While these results are suggestive given the small number of researchers represented in each field, greater interdisciplinary collaboration may allow researchers to solve existing disagreements regarding the term reciprocity. In particular, economists and psychologists may consider collaborating on comparisons of cooperative transfers that occur in formal/marketbased contexts to those that occur in informal/relationship-based contexts. Similarly, economists and sociologists could consider collaborations on the topic of cooperative transfers that involve dimensions of debt or account keeping.

\section{Conclusion}

Cooperation can take many shapes and forms, from coordinated action such as alarm calling, to gift giving in mate seeking and coalition formation, caring for the young, communal food sharing, reputation-based giving, punishment, intergroup conflict, and market exchanges. 
Given the complexity and diversity of cooperation in which humans and other species engage, it is no surprise that so many unique dimensions of the term reciprocity have been offered in the literature thus far.

Overall, results indicate that researchers agree more about what reciprocity is not than what it is: i.e. it is not unconditional giving. We offer a potential framework here that is based on experts' ratings of reciprocity terms. As the scholarly community moves forward, it may be valuable to refrain from describing special cases, or dimensions, of cooperation as some kind of reciprocity, and instead adopt terms such as balanced, reputation-based, debt-based, and unconditional transfers. This could facilitate communication among scientists and, ultimately, may lead to new discoveries about the nature of cooperation in humans and other animals.

\section{Acknowledgments}

We thank members of the Human Generosity Project (humangenerosity.org/) for their feedback and contributions to this manuscript. 


\section{References}

Alexander, R. D. (1977) Natural selection and the analysis of human sociality. In: Changing scenes in the natural sciences, ed. C. E. Goulden, 283-337. Philadelphia Academy of Natural Sciences, pp. 283-337.

Alexander, R. D. (1987) The biology of moral systems. Aldine de Gruyter.

Axelrod, R., \& Hamilton, W. D. (1981). The evolution of cooperation. Science, 211(4489), 13901396.

Axelrod, R. (1984) The evolution of cooperation. Basic Books.

Berbesque, J. C., Wood, B. M., Crittenden, A. N., Mabulla, A. \& Marlowe, F. W. Eat first, share later: Hadza hunter-gatherer men consume more while foraging than in central places. Evolution and Human Behavior, 37, 281-286 (2016).

Bird, R.B., Bird, D.W., Smith, E.A. and Kushnick, G.C., 2002. Risk and reciprocity in Meriam food sharing. Evolution and Human Behavior, 23(4), pp.297-321.

Boyd, R., \& Richerson, P. J. (1989). The evolution of indirect reciprocity. Social networks, 11(3), 213-236.

Brosnan, S. F., \& de Waal, F. B. M. (2002). A proximate perspective on reciprocal altruism. Human Nature, 13(1), 129-152.

Burgoon, J.K., Dillman, L. and Stem, L.A. (1993). Adaptation in dyadic interaction: Defining and operationalizing patterns of reciprocity and compensation. Communication Theory, 3(4), pp.295-316.

Carter, G. (2014). The reciprocity controversy. Animal Behavior and Cognition 1(3):368-386. Cashdan, E. Hunters and gatherers: Economic behavior in bands. in Economic Anthropology (ed. Plattner, S.) 21-48 (Stanford University Press, 1989).

Connor, R. C. (1986) Pseudoreciprocity: Investing in mutualism. Animal Behaviour 34:15621566.

Cronk, L., \& Aktipis, A. (2021). Design principles for risk-pooling systems. Nature Human 
Behaviour. https://doi.org/10.1038/s41562-021-01121-9.

Cronk, L., and B. L. Leech. (2013). Meeting at Grand Central: Understanding the Social and Evolutionary Roots of Cooperation. Princeton: Princeton University Press.

Cronk, L., Berbesque, C., Conte, T., Gervais, M., Iyer, P., McCarthy, B., Sonkoi, D., Townsend, C., \& Aktipis, A. (2019). Managing Risk Through Cooperation: Need-Based Transfers and Risk Pooling Among the Societies of the Human Generosity Project. In L. R. Lozny \& T. H. McGovern (Eds.), Global Perspectives on Long Term Community Resource Management (pp. 41-75). Springer International Publishing.

Dictionary, O. E. (1989). Oxford English Dictionary. Simpson, JA \& Weiner, ESC.

Faul, F., Erdfelder, E., Lang, A.-G., \& Buchner, A. (2007). G*Power 3: a flexible statistical power analysis program for the social, behavioral, and biomedical sciences. Behavior Research Methods, 39(2), 175-191.

Fleiss, J. L., \& Cohen, J. (1973). The Equivalence of Weighted Kappa and the Intraclass Correlation Coefficient as Measures of Reliability. Educational and Psychological Measurement, 33(3), 613-619.

Floyd, S., Rossi, G., Baranova, J., Blythe, J., Dingemanse, M., Kendrick, K. H., Zinken, J., \& Enfield, N. J. (2018). Universals and cultural diversity in the expression of gratitude. Royal Society Open Science, 5(5), 180391.

Gintis, H. (2000) Strong reciprocity and human sociality. Journal of Theoretical Biology 206:169-179.

Gouldner, A. W. (1960) The norm of reciprocity: A preliminary statement. American Sociological Review 25(2):161-178.

Guala, F. (2011) Reciprocity: Weak or strong? What punishment experiments do (and do not) demonstrate. Behavioral and Brain Sciences, 35:1-59.

Gurven, M. (2006) The evolution of contingent cooperation. Current Anthropology 47(1):185192. 
Horita, Y., Takezawa, M., Kinjo, T., Nakawake, Y., \& Masuda, N. (2016). Transient nature of cooperation by pay-it-forward reciprocity. Scientific Reports, 6, 19471.

Isaac, G. L. Aspects of human evolution. in Evolution from Molecules to Man (ed. Bendall, D. S.) 509-543 (Cambridge University Press, 1983).

Knekta, E., Runyon, C., \& Eddy, S. (2019). One Size Doesn't Fit All: Using Factor Analysis to Gather Validity Evidence When Using Surveys in Your Research. CBE Life Sciences Education, 18(1), rm1.

Lévi-Strauss, C. (1969) The elementary structures of kinship. Revised edition. Trans. J. H. Bell, J. R. von Sturmer, \& R. Needham. Beacon Press.

Malinowski, B. (1926) Crime and custom in savage society. Routledge \& Kegan Paul. Marlowe, F. W. Hunter-gatherers and human evolution. Evolutionary Anthropology: Issues, News, and Reviews, 14, 54-67 (2005).

Mauss, M. (2002). The Gift: The Form and Reason for Exchange in Archaic Societies. Routledge.

Mesterton-Gibbons, M. (2019). An introduction to game-theoretic modelling (Vol. 37). American Mathematical Soc.

Mundfrom, D. J., Shaw, D. G., \& Tian Lu Ke. (2005). Minimum Sample Size Recommendations for Conducting Factor Analyses. International Journal of Testing, 5(2), 159-168.

Moody, M. (2008). Serial reciprocity: A preliminary statement. Sociological Theory, 26(2), 130151.

Nowak, M. A., \& Sigmund, K. (2005). Evolution of indirect reciprocity. Nature, 437(7063), 12911298.

Nowak, M. A. (2006). Evolutionary dynamics: Exploring the equations of life. Belknap Press.

Pfeiffer, T., Rutte, C., Killingback, T., Taborsky, M., \& Bonhoeffer, S. (2005). Evolution of cooperation by generalized reciprocity. Proceedings of the Royal Society B, 272:11151120. 
Polanyi, K. (1944). The great transformation: The political and economic origins of our time. Boston: Beacon Press.

Price, J. A. (1962) Washoe economy. Nevada State Museum Anthropological Paper 6.

Revelle, W. (2018). psych: Procedures for psychological, psychometric, and personality research. $R$ Package Version, 1(10).

Sahlins, M. D. (1965) On the sociology of primitive exchange. In: The relevance of models for social anthropology, ed. M. Banton. Tavistock. Reprinted in Stone age economics (1972, Transaction).

Suranovic, S. M. (2000). A positive analysis of fairness with applications to international trade. World Economy, 23(3), 283-307.

Thurnwald, R. (1932) Economics in primitive communities. Oxford University Press.

Trivers, R. L. (1971) The evolution of reciprocal altruism. The Quarterly Review of Biology, 46:35-57.

Trivers, R. (1985). Social Evolution. Benjamin/Cummings Publishing Company.

Wiley, R. H., \& Rabenold, K. N. (1984) The evolution of cooperative breeding by delayed reciprocity and queuing for favorable social positions. Evolution 38: 609-621.

Zaiontz, C. (2020). Real Statistics Resource Pack software (Release 7.6) [Computer software]. https://www.real-statistics.com/ 


\title{
Online Supplement
}

\author{
What is Reciprocity? \\ A Review and Expert-based Classification of Cooperative Transfers \\ Diego Guevara Beltran ${ }^{1}$, Jessica Ayers ${ }^{1}$, Andres Munoz ${ }^{1}$, Lee Cronk ${ }^{2}$, Athena Aktipis ${ }^{1}$ \\ ${ }^{1}$ Department of Psychology, Arizona State University \\ ${ }^{2}$ Department of Anthropology, Rutgers University - New Brunswick
}

S1. Supplemental Tables 1-14

S2. Qualitative expert responses of the term reciprocity 


\section{Table S1}

Paired-samples $t$-tests of the perceived consensus of the use of the term reciprocity

\begin{tabular}{lcccccc}
\hline Comparison & $t(66)$ & $p$ & $M_{\text {diff }}$ & $95 \% \mathrm{Cl}$ & $d$ \\
\hline Own academic field - other academic fields & 8.31 & $<0.001$ & 1.03 & 0.78 & 1.28 & 1.05 \\
Own academic field - public & 4.66 & $<0.001$ & 0.93 & 0.53 & 1.32 & 0.57 \\
Other academic fields - public & -0.56 & 0.58 & -0.10 & -0.48 & 0.27 & -0.07 \\
\hline
\end{tabular}

Note. Participants rated their perceived level of consensus on the use of the term reciprocity (1 = no consensus, 7 = absolute consensus $)$. 
Table S2

\section{Exploratory factor analysis of scholarly definitions of reciprocity}

\begin{tabular}{|c|c|c|c|c|c|}
\hline Definition & Label & Balanced & Reputation & Debt & Unconditional \\
\hline Heteromorphic reciprocity & Exchange of things that are concretely different but of equal value & 0.90 & 0.01 & -0.06 & 0.10 \\
\hline Balanced reciprocity & Transfers of equal value & 0.67 & -0.02 & 0.09 & 0.12 \\
\hline Homeomorphic reciprocity & Exchange of things that are the same & 0.67 & -0.28 & 0.27 & 0.02 \\
\hline Attitudinal Recirpocity & $\begin{array}{l}\text { When parties mirror one another's attitudes, exchanging favors on the } \\
\text { spot }\end{array}$ & 0.62 & 0.36 & -0.07 & -0.06 \\
\hline Delayed Reciprocity & Payment with delay between initial transfer and repayment & 0.54 & -0.10 & 0.25 & -0.12 \\
\hline Interpersonal Reciprocity & $\begin{array}{l}\text { The process of behavioral adaptation in which one responds, in similar } \\
\text { direction, to a partner's behaviors with behaviors of comparable } \\
\text { functional value }\end{array}$ & 0.46 & 0.07 & -0.04 & 0.03 \\
\hline Reciprocity II & $\begin{array}{l}\text { A situation where today's giving will be recompensed by tomorrow's } \\
\text { taking }\end{array}$ & 0.42 & 0.23 & 0.18 & -0.04 \\
\hline Reciprocal Altruismb & The trading of altruistic acts & 0.41 & 0.13 & 0.18 & -0.01 \\
\hline Reciprocation & $\begin{array}{l}\text { Action or practice of offering a response in kind, or of doing one thing } \\
\text { in return for another }\end{array}$ & 0.35 & 0.15 & 0.26 & -0.13 \\
\hline $\begin{array}{l}\text { Symmetry-based } \\
\text { reciprocity }\end{array}$ & $\begin{array}{l}\text { When mutual affection between two parties prompts similar behavior in } \\
\text { both directions without the need to keep track of give-and-take, so long } \\
\text { as the relationship remains satisfactory }\end{array}$ & 0.30 & 0.25 & -0.18 & 0.24 \\
\hline Tit-forTat reciprocity & $\begin{array}{l}\text { When individuals cooperate if the other party cooperates, and defect if } \\
\text { the other party defects }\end{array}$ & 0.29 & 0.14 & 0.22 & -0.28 \\
\hline Reciprocal Altruisma & Acting altruistically towards another who has already acted altruistically & -0.01 & 0.87 & 0.04 & -0.04 \\
\hline Generalized reciprocity II & $\begin{array}{l}\text { General tendency to be altruistic to others when others have been } \\
\text { altruistic to you }\end{array}$ & 0.12 & 0.73 & -0.22 & -0.01 \\
\hline $\begin{array}{l}\text { Upstream indirect } \\
\text { reciprocity }\end{array}$ & $\begin{array}{l}\text { An act of altruism causes the recipient to perform a later act of altruism } \\
\text { in the benefit of a third party }\end{array}$ & -0.16 & 0.68 & 0.20 & 0.18 \\
\hline $\begin{array}{l}\text { Downstream indirect } \\
\text { reciprocity }\end{array}$ & $\begin{array}{l}\text { The performer of an act of altruism is more likely to be the recipient of } \\
\text { a later act of altruism }\end{array}$ & 0.02 & 0.60 & 0.24 & 0.08 \\
\hline Indirect reciprocity & When return is expected from someone other than recipient of benefit & 0.04 & 0.53 & 0.30 & 0.12 \\
\hline
\end{tabular}




\begin{tabular}{|c|c|c|c|c|c|}
\hline Positive reciprocity & $\begin{array}{l}\text { An action that has a positive effect upon someone else is repaid with } \\
\text { an action that has approximately equal positive effect upon another }\end{array}$ & 0.05 & 0.50 & 0.10 & 0.17 \\
\hline Pseudoreciprocity & $\begin{array}{l}\text { When the return benefit for a beneficent act is a by-product or } \\
\text { incidental effect of egoistic behavior by the recipient of the beneficent } \\
\text { act }\end{array}$ & -0.01 & 0.24 & 0.16 & 0.26 \\
\hline Negative rec. II & $\begin{array}{l}\text { An action that has a negative effect upon someone else is repaid with } \\
\text { an action that has approximately equal negative effect upon another }\end{array}$ & 0.08 & 0.23 & 0.06 & -0.02 \\
\hline Direct Reciprocity & When return is expected from the recipient of the benefit & -0.01 & 0.09 & 0.80 & -0.05 \\
\hline Calculated reciprocity & $\begin{array}{l}\text { When individuals keep track of the benefits they exchange with } \\
\text { particular partners, which helps them decide to whom to return favors }\end{array}$ & 0.15 & 0.17 & 0.58 & -0.19 \\
\hline Risk reduction reciprocity & Giving with the expectation of equivalent return & 0.24 & -0.08 & 0.56 & 0.25 \\
\hline Weak Reciprocity II & A requirement that givers receive a benefit & 0.20 & 0.23 & 0.45 & 0.09 \\
\hline Reciprocity I & $\begin{array}{l}\text { A chain of gifts and counter gifts, which in the long run balance, } \\
\text { benefiting both sides equally }\end{array}$ & 0.26 & 0.17 & 0.43 & 0.13 \\
\hline Reciprocity III & $\begin{array}{l}\text { Gifts exchanged immediately or on the condition that return gifts will be } \\
\text { given in the future }\end{array}$ & 0.37 & 0.20 & 0.39 & -0.03 \\
\hline Contingent Reciprocity & Giving that is contingent on past giving & 0.15 & 0.28 & 0.33 & -0.31 \\
\hline Generalized reciprocity I & Non-conditional sharing and giving of assistance & 0.19 & -0.01 & -0.03 & 0.69 \\
\hline Network reciprocity & Non-conditional altruism favored by selection on social networks & 0.14 & 0.21 & -0.16 & 0.68 \\
\hline Negative Reciprocity I & Acquisition of benefit without intent to repay & -0.26 & -0.01 & 0.24 & 0.60 \\
\hline Strong reciprocity II & Non-conditional altruism and punishment favored by group selection & 0.03 & 0 & 0.02 & 0.48 \\
\hline
\end{tabular}

Note. Researchers $(n=70)$ were asked "Is this reciprocity?" for each scenario $(1=$ definitely not reciprocity, $7=$ definitely reciprocity).

Numbers in bold reflect factor loadings $=<0.40$. 


\section{Table S3}

\section{Exploratory factor analysis of scholarly definitions of reciprocity (removing participants who failed to report sample characteristics)}

\begin{tabular}{|c|c|c|c|c|c|}
\hline Definition & Label & Balanced & Reputation & Debt & Unconditional \\
\hline Heteromorphic reciprocity & Exchange of things that are concretely different but of equal value & 0.90 & 0.01 & -0.07 & 0.11 \\
\hline Homeomorphic reciprocity & Exchange of things that are the same & 0.67 & -0.29 & 0.28 & 0.02 \\
\hline Balanced reciprocity & Transfers of equal value & 0.66 & -0.02 & 0.09 & 0.13 \\
\hline Attitudinal Recirpocity & When parties mirror one another's attitudes, exchanging favors on the spot & 0.62 & 0.35 & -0.06 & -0.05 \\
\hline Delayed Reciprocity & Payment with delay between initial transfer and repayment & 0.57 & -0.1 & 0.21 & -0.13 \\
\hline Interpersonal Reciprocity & $\begin{array}{l}\text { The process of behavioral adaptation in which one responds, in similar } \\
\text { direction, to a partner's behaviors with behaviors of comparable functional } \\
\text { value }\end{array}$ & 0.47 & 0.07 & -0.05 & 0.04 \\
\hline Reciprocity II & A situation where today's giving will be recompensed by tomorrow's taking & 0.45 & 0.23 & 0.18 & -0.06 \\
\hline Reciprocal Altruismb & The trading of altruistic acts & 0.42 & 0.15 & 0.13 & -0.01 \\
\hline Reciprocation & $\begin{array}{l}\text { Action or practice of offering a response in kind, or of doing one thing in } \\
\text { return for another }\end{array}$ & 0.36 & 0.16 & 0.22 & -0.14 \\
\hline $\begin{array}{l}\text { Symmetry-based } \\
\text { reciprocity }\end{array}$ & $\begin{array}{l}\text { When mutual affection between two parties prompts similar behavior in } \\
\text { both directions without the need to keep track of give-and-take, so long as } \\
\text { the relationship remains satisfactory }\end{array}$ & 0.29 & 0.25 & -0.16 & 0.26 \\
\hline Tit-forTat reciprocity & $\begin{array}{l}\text { When individuals cooperate if the other party cooperates, and defect if the } \\
\text { other party defects }\end{array}$ & 0.28 & 0.14 & 0.19 & -0.28 \\
\hline Reciprocal Altruisma & Acting altruistically towards another who has already acted altruistically & -0.03 & 0.90 & 0.01 & -0.02 \\
\hline Generalized reciprocity II & $\begin{array}{l}\text { General tendency to be altruistic to others when others have been altruistic } \\
\text { to you }\end{array}$ & 0.13 & 0.72 & -0.22 & 0 \\
\hline $\begin{array}{l}\text { Upstream indirect } \\
\text { reciprocity }\end{array}$ & $\begin{array}{l}\text { An act of altruism causes the recipient to perform a later act of altruism in } \\
\text { the benefit of a third party }\end{array}$ & -0.14 & 0.68 & 0.23 & 0.17 \\
\hline $\begin{array}{l}\text { Downstream indirect } \\
\text { reciprocity }\end{array}$ & $\begin{array}{l}\text { The performer of an act of altruism is more likely to be the recipient of a } \\
\text { later act of altruism }\end{array}$ & 0.04 & 0.60 & 0.23 & 0.08 \\
\hline Indirect reciprocity & When return is expected from someone other than recipient of benefit & 0.05 & 0.54 & 0.28 & 0.10 \\
\hline Positive reciprocity & An action that has a positive effect upon someone else is repaid with an & 0.05 & 0.50 & 0.11 & 0.16 \\
\hline
\end{tabular}


action that has approximately equal positive effect upon another

Pseudoreciprocity

When the return benefit for a beneficent act is a by-product or incidental effect of egoistic behavior by the recipient of the beneficent act

\begin{tabular}{|c|c|c|c|c|c|}
\hline Negative rec. II & $\begin{array}{l}\text { An action that has a negative effect upon someone else is repaid with an } \\
\text { action that has approximately equal negative effect upon another }\end{array}$ & 0.06 & 0.22 & 0.07 & -0.01 \\
\hline Direct Reciprocity & When return is expected from the recipient of the benefit & -0.02 & 0.09 & 0.82 & -0.05 \\
\hline Risk reduction reciprocity & Giving with the expectation of equivalent return & 0.22 & -0.08 & 0.58 & 0.26 \\
\hline Calculated reciprocity & $\begin{array}{l}\text { When individuals keep track of the benefits they exchange with particular } \\
\text { partners, which helps them decide to whom to return favors }\end{array}$ & 0.18 & 0.18 & 0.57 & -0.21 \\
\hline Reciprocity I & $\begin{array}{l}\text { A chain of gifts and counter gifts, which in the long run balance, benefiting } \\
\text { both sides equally }\end{array}$ & 0.28 & 0.17 & 0.44 & 0.11 \\
\hline Weak Reciprocity II & A requirement that givers receive a benefit & 0.23 & 0.25 & 0.41 & 0.07 \\
\hline Reciprocity III & $\begin{array}{l}\text { Gifts exchanged immediately or on the condition that return gifts will be } \\
\text { given in the future }\end{array}$ & 0.37 & 0.21 & 0.39 & -0.02 \\
\hline Generalized reciprocity I & Non-conditional sharing and giving of assistance & 0.18 & 0 & -0.03 & 0.69 \\
\hline Network reciprocity & Non-conditional altruism favored by selection on social networks & 0.16 & 0.22 & -0.15 & 0.68 \\
\hline Strong reciprocity II & Non-conditional altruism and punishment favored by group selection & 0.04 & -0.01 & 0.05 & 0.48 \\
\hline Negative Reciprocity I & Acquisition of benefit without intent to repay & -0.27 & 0.01 & 0.24 & 0.60 \\
\hline Contingent Reciprocity & Giving that is contingent on past giving & 0.16 & 0.30 & 0.30 & -0.33 \\
\hline
\end{tabular}

Note. Researchers $(n=67)$ were asked "Is this reciprocity?" for each scenario $(1=$ definitely not reciprocity, $7=$ definitely reciprocity).

Numbers in bold reflect factor loadings $=<0.40$. 


\section{Table S4}

Paired-samples t-tests of reciprocity ratings (scholarly definition factors)

\begin{tabular}{lcccccc}
\hline Comparison & $t(66)$ & $p$ & $M_{\text {diff }}$ & \multicolumn{2}{c}{$95 \% \mathrm{Cl}$} & $d$ \\
\hline Balanced - Reputation & -0.75 & 0.45 & -0.15 & -0.55 & 0.25 & -0.09 \\
Balanced - Debt & -0.73 & 0.47 & -0.12 & -0.44 & 0.20 & -0.09 \\
Balanced - Unconditional & 13.01 & $<0.001$ & 2.43 & 2.06 & 2.80 & 1.60 \\
Reputation - Debt & 0.19 & 0.85 & 0.03 & -0.33 & 0.40 & 0.02 \\
Reputation - Unconditional & 13.69 & $<0.001$ & 2.58 & 2.20 & 2.96 & 1.67 \\
\hline
\end{tabular}

Note. Analyses show comparisons after removing 18 participants who failed to report items assessing academic expertise. 


\section{Table S5}

Mean reciprocity values of scholarly definition factors by academic field

\begin{tabular}{|c|c|c|c|c|}
\hline Factor & Field & $n$ & $M$ & $S D$ \\
\hline \multirow{6}{*}{ Balanced } & Anthropology & 6 & 3.94 & 2.34 \\
\hline & Biology & 16 & 4.69 & 1.39 \\
\hline & Economics & 12 & 3.18 & 1.41 \\
\hline & Psychology & 16 & 4.67 & 1.12 \\
\hline & Sociology & 5 & 4.93 & 1.69 \\
\hline & All fields & 55 & 4.29 & 1.56 \\
\hline \multirow{6}{*}{ Reputation-based } & Anthropology & 6 & 4.72 & 2.51 \\
\hline & Biology & 16 & 4.69 & 1.16 \\
\hline & Economics & 12 & 3.96 & 1.43 \\
\hline & Psychology & 16 & 4.39 & 1.44 \\
\hline & Sociology & 5 & 4.83 & 1.85 \\
\hline & All fields & 55 & 4.46 & 1.52 \\
\hline \multirow{6}{*}{ Debt-based } & Anthropology & 6 & 4.17 & 2.48 \\
\hline & Biology & 16 & 4.59 & 1.56 \\
\hline & Economics & 12 & 3.38 & 1.42 \\
\hline & Psychology & 16 & 4.78 & 1.49 \\
\hline & Sociology & 5 & 5.92 & 1.03 \\
\hline & All fields & 55 & 4.45 & 1.69 \\
\hline \multirow{6}{*}{ Unconditional } & Anthropology & 6 & 2.04 & 1.26 \\
\hline & Biology & 16 & 1.58 & 0.80 \\
\hline & Economics & 12 & 1.40 & 0.49 \\
\hline & Psychology & 16 & 2.27 & 1.20 \\
\hline & Sociology & 5 & 1.85 & 1.24 \\
\hline & All fields & 55 & 1.81 & 1.01 \\
\hline
\end{tabular}




\section{Table S6}

Frequencies of researchers' ratings of scholarly definitions of reciprocity and level of agreement

\begin{tabular}{|c|c|c|c|c|c|c|c|}
\hline Definition & $n$ & Not & Somewhat & Is & Kappa & \multicolumn{2}{|c|}{$95 \% \mathrm{Cl}$} \\
\hline Negative Reciprocity I & 78 & 75 & 3 & 0 & 0.92 & 0.89 & 0.96 \\
\hline Strong reciprocity II & 77 & 70 & 2 & 5 & 0.83 & 0.80 & 0.86 \\
\hline Pseudoreciprocity & 73 & 61 & 2 & 10 & 0.70 & 0.67 & 0.74 \\
\hline Generalized reciprocity I & 79 & 66 & 5 & 8 & 0.70 & 0.67 & 0.73 \\
\hline Reciprocation & 77 & 10 & 5 & 62 & 0.65 & 0.62 & 0.68 \\
\hline Network reciprocity & 76 & 61 & 8 & 7 & 0.64 & 0.62 & 0.67 \\
\hline Tit-forTat reciprocity & 77 & 11 & 6 & 60 & 0.61 & 0.58 & 0.64 \\
\hline Reciprocity I & 77 & 12 & 11 & 54 & 0.49 & 0.46 & 0.52 \\
\hline Calculated reciprocity & 76 & 22 & 4 & 50 & 0.46 & 0.43 & 0.49 \\
\hline Generalized reciprocity II & 75 & 13 & 12 & 50 & 0.44 & 0.42 & 0.47 \\
\hline Contingent Reciprocity & 77 & 13 & 13 & 51 & 0.44 & 0.41 & 0.47 \\
\hline Attitudinal Recirpocity & 77 & 23 & 7 & 47 & 0.40 & 0.37 & 0.43 \\
\hline Reciprocity III & 68 & 18 & 9 & 41 & 0.38 & 0.34 & 0.41 \\
\hline Reciprocal Altruismb & 75 & 19 & 12 & 44 & 0.35 & 0.33 & 0.38 \\
\hline Positive reciprocity & 77 & 25 & 9 & 43 & 0.35 & 0.32 & 0.37 \\
\hline Direct Reciprocity & 77 & 36 & 7 & 34 & 0.33 & 0.30 & 0.36 \\
\hline Reciprocal Altruismª & 78 & 23 & 12 & 43 & 0.33 & 0.30 & 0.35 \\
\hline Risk reduction reciprocity & 76 & 27 & 9 & 40 & 0.32 & 0.30 & 0.35 \\
\hline Indirect reciprocity & 76 & 42 & 12 & 22 & 0.32 & 0.30 & 0.35 \\
\hline Interpersonal Reciprocity & 74 & 19 & 14 & 41 & 0.32 & 0.29 & 0.35 \\
\hline Downstream indirect reciprocity & 78 & 26 & 11 & 41 & 0.31 & 0.29 & 0.34 \\
\hline Upstream indirect reciprocity & 78 & 31 & 9 & 38 & 0.31 & 0.28 & 0.34 \\
\hline Weak Reciprocity II & 78 & 40 & 14 & 24 & 0.29 & 0.26 & 0.32 \\
\hline Homeomorphic reciprocity & 79 & 36 & 11 & 32 & 0.29 & 0.26 & 0.31 \\
\hline Delayed Reciprocity & 76 & 35 & 11 & 30 & 0.28 & 0.26 & 0.31 \\
\hline Negative rec. II & 77 & 35 & 13 & 29 & 0.27 & 0.24 & 0.30 \\
\hline Symmetry-based reciprocity & 77 & 26 & 16 & 35 & 0.25 & 0.23 & 0.28 \\
\hline Reciprocity II & 75 & 27 & 16 & 32 & 0.24 & 0.21 & 0.27 \\
\hline Heteromorphic reciprocity & 77 & 28 & 17 & 32 & 0.24 & 0.21 & 0.26 \\
\hline Balanced reciprocity & 76 & 32 & 17 & 27 & 0.24 & 0.21 & 0.26 \\
\hline
\end{tabular}

Note. Kappa's in bold show definitions that reached an above acceptable level of agreement. 


\section{Table S7}

\section{Exploratory factor analysis of social scenarios (4-factor solution)}

\begin{tabular}{|c|c|c|c|c|}
\hline Hypothetical Scenario & Balance/Debt & Retaliation & Unconditional & Reputation \\
\hline Skyler gives Chris some juice. Three months later, Chris gives Skyler some bread. & 0.70 & 0.03 & 0.14 & 0.22 \\
\hline $\begin{array}{l}\text { Skyler is hungry and has no food. Chris gives Skyler some bread. On the next day, Chris is } \\
\text { hungry and has no food. Skyler gives Chris some bread. }\end{array}$ & 0.69 & -0.06 & -0.20 & -0.08 \\
\hline $\begin{array}{l}\text { Chris gives a birthday present to Skyler. Three months later, Skyler gives a birthday present to } \\
\text { Chris. }\end{array}$ & 0.66 & 0.09 & 0.19 & -0.26 \\
\hline $\begin{array}{l}\text { Skyler is hungry and has no food. Chris gives Skyler some bread once a week. One day, Chris } \\
\text { is thirsty and has no water. Skyler gives Chris some water. }\end{array}$ & 0.62 & -0.03 & -0.07 & 0.07 \\
\hline Skyler gives Chris some juice and Chris gives Skyler some bread in return. & 0.51 & 0.19 & 0.14 & 0.21 \\
\hline Skyler steals bread from Chris. & -0.40 & -0.01 & 0.29 & -0.02 \\
\hline Skyler gives Chris a cooked lobster and Chris gives Skyler a sip of soda in return. & 0.33 & 0.10 & 0.14 & 0.22 \\
\hline Skyler gives Chris some money in exchange for some bread. & 0.21 & 0.21 & 0.04 & -0.03 \\
\hline Chris punches Skyler and Skyler punches Chris in response. & -0.01 & 0.96 & -0.02 & 0.05 \\
\hline Chris steals Skyler's bread. Three months later, Skyler steals Chris' bread. & 0.04 & 0.75 & 0.02 & -0.06 \\
\hline Skyler is hungry and has no food. Chris gives Skyler some bread. Skyler gives Chris a smile. & -0.01 & 0.03 & 0.70 & -0.06 \\
\hline $\begin{array}{l}\text { Skyler is hungry and asks for bread from Chris every day for a week. One day, Chris is hungry } \\
\text { and asks for water from Skyler. }\end{array}$ & 0.07 & -0.10 & 0.57 & 0.21 \\
\hline Chris smiles at Skyler and Skyler smiles back at Chris. & 0.06 & 0.26 & 0.47 & -0.10 \\
\hline Chris gives Skyler some bread without expecting anything in return from Skyler. & -0.03 & -0.21 & 0.40 & 0.12 \\
\hline $\begin{array}{l}\text { Skyler spoke with Chris about his experience in class. Chris listened and told Skyler about a } \\
\text { similar experience he had as a student. }\end{array}$ & 0.10 & 0.15 & 0.28 & -0.05 \\
\hline $\begin{array}{l}\text { Chris gives Skyler some bread and Alex sees the exchange taking place. Then, Alex gives } \\
\text { Chris some bread. }\end{array}$ & -0.07 & 0.15 & -0.03 & 0.61 \\
\hline Chris gives Skyler some bread. Then, Skyler gives Alex some bread. & 0.19 & -0.10 & 0.08 & 0.58 \\
\hline
\end{tabular}

Note. Researchers $(n=76)$ were asked "Is this reciprocity?" for each scenario $(1=$ definitely not reciprocity, $7=$ definitely reciprocity).

Numbers in bold reflect factor loadings $=<0.40$. 


\section{Table S8}

\section{Exploratory factor analysis of social scenarios (3-factor solution)}

\begin{tabular}{|c|c|c|c|}
\hline Hypothetical Scenario & Balance/Debt & Retaliation & Unconditional \\
\hline Skyler gives Chris some juice. Three months later, Chris gives Skyler some bread. & 0.79 & 0.01 & 0.15 \\
\hline $\begin{array}{l}\text { Skyler is hungry and has no food. Chris gives Skyler some bread. On the next day, Chris is hungry } \\
\text { and has no food. Skyler gives Chris some bread. }\end{array}$ & 0.64 & -0.03 & -0.27 \\
\hline $\begin{array}{l}\text { Skyler is hungry and has no food. Chris gives Skyler some bread once a week. One day, Chris is } \\
\text { thirsty and has no water. Skyler gives Chris some water. }\end{array}$ & 0.64 & -0.03 & -0.09 \\
\hline Skyler gives Chris some juice and Chris gives Skyler some bread in return. & 0.60 & 0.16 & 0.16 \\
\hline Chris gives a birthday present to Skyler. Three months later, Skyler gives a birthday present to Chris. & 0.52 & 0.23 & 0.04 \\
\hline Skyler gives Chris a cooked lobster and Chris gives Skyler a sip of soda in return. & 0.42 & 0.06 & 0.19 \\
\hline Skyler steals bread from Chris. & -0.41 & 0.02 & 0.30 \\
\hline Chris gives Skyler some bread. Then, Skyler gives Alex some bread. & 0.39 & -0.22 & 0.24 \\
\hline $\begin{array}{l}\text { Chris gives Skyler some bread and Alex sees the exchange taking place. Then, Alex gives Chris some } \\
\text { bread. }\end{array}$ & 0.16 & -0.03 & 0.16 \\
\hline Chris punches Skyler and Skyler punches Chris in response. & 0.03 & 0.85 & -0.01 \\
\hline Chris steals Skyler's bread. Three months later, Skyler steals Chris' bread. & 0 & 0.80 & -0.02 \\
\hline Skyler gives Chris some money in exchange for some bread. & 0.20 & 0.23 & 0.01 \\
\hline $\begin{array}{l}\text { Skyler is hungry and asks for bread from Chris every day for a week. One day, Chris is hungry and } \\
\text { asks for water from Skyler. }\end{array}$ & 0.17 & -0.08 & 0.62 \\
\hline Skyler is hungry and has no food. Chris gives Skyler some bread. Skyler gives Chris a smile. & -0.01 & 0.15 & 0.58 \\
\hline Chris gives Skyler some bread without expecting anything in return from Skyler. & 0.02 & -0.2 & 0.44 \\
\hline Chris smiles at Skyler and Skyler smiles back at Chris. & 0.04 & 0.36 & 0.38 \\
\hline $\begin{array}{l}\text { Skyler spoke with Chris about his experience in class. Chris listened and told Skyler about a similar } \\
\text { experience he had as a student. }\end{array}$ & 0.08 & 0.22 & 0.23 \\
\hline
\end{tabular}

Note. Researchers $(n=76)$ were asked "Is this reciprocity?" for each scenario $(1=$ definitely not reciprocity, $7=$ definitely reciprocity).

Numbers in bold reflect factor loadings $=<0.40$. 


\section{Table S9}

Exploratory factor analysis of social scenarios (3-factor solution, removing participants who failed to report sample characteristics)

\begin{tabular}{|c|c|c|c|}
\hline Hypothetical Scenario & Balance/Debt & Retaliation & Unconditional \\
\hline Skyler gives Chris some juice. Three months later, Chris gives Skyler some bread. & 0.87 & -0.02 & 0.12 \\
\hline $\begin{array}{l}\text { Skyler is hungry and has no food. Chris gives Skyler some bread once a week. One day, Chris is thirsty and } \\
\text { has no water. Skyler gives Chris some water. }\end{array}$ & 0.74 & -0.01 & -0.12 \\
\hline Skyler gives Chris some juice and Chris gives Skyler some bread in return. & 0.64 & 0.19 & 0.11 \\
\hline $\begin{array}{l}\text { Skyler is hungry and has no food. Chris gives Skyler some bread. On the next day, Chris is hungry and has } \\
\text { no food. Skyler gives Chris some bread. }\end{array}$ & 0.57 & 0.06 & -0.22 \\
\hline Skyler gives Chris a cooked lobster and Chris gives Skyler a sip of soda in return. & 0.52 & 0.05 & 0.1 \\
\hline Chris gives Skyler some bread. Then, Skyler gives Alex some bread. & 0.51 & -0.3 & 0.08 \\
\hline Chris gives a birthday present to Skyler. Three months later, Skyler gives a birthday present to Chris. & 0.46 & 0.27 & 0.09 \\
\hline Skyler steals bread from Chris. & -0.38 & -0.04 & 0.33 \\
\hline Chris gives Skyler some bread and Alex sees the exchange taking place. Then, Alex gives Chris some bread. & 0.26 & -0.08 & -0.02 \\
\hline Chris punches Skyler and Skyler punches Chris in response. & 0.05 & 0.82 & 0.03 \\
\hline Chris steals Skyler's bread. Three months later, Skyler steals Chris' bread. & 0 & 0.81 & -0.03 \\
\hline Skyler gives Chris some money in exchange for some bread. & 0.28 & 0.32 & -0.05 \\
\hline Skyler is hungry and has no food. Chris gives Skyler some bread. Skyler gives Chris a smile. & 0.01 & 0.04 & 0.64 \\
\hline $\begin{array}{l}\text { Skyler is hungry and asks for bread from Chris every day for a week. One day, Chris is hungry and asks for } \\
\text { water from Skyler. }\end{array}$ & 0.23 & -0.14 & 0.55 \\
\hline Chris smiles at Skyler and Skyler smiles back at Chris. & 0.04 & 0.36 & 0.54 \\
\hline Chris gives Skyler some bread without expecting anything in return from Skyler. & 0.05 & -0.22 & 0.43 \\
\hline $\begin{array}{l}\text { Skyler spoke with Chris about his experience in class. Chris listened and told Skyler about a similar } \\
\text { experience he had as a student. }\end{array}$ & 0.01 & 0.26 & 0.25 \\
\hline
\end{tabular}

Note. Researchers $(n=67)$ were asked "Is this reciprocity?" for each scenario $(1=$ definitely not reciprocity, $7=$ definitely reciprocity).

Numbers in bold reflect factor loadings $=<0.40$. 


\section{Table 10}

Exploratory factor analysis of social scenarios (4-factor solution, removing participants who failed to report sample characteristics)

\begin{tabular}{|c|c|c|c|c|}
\hline Hypothetical Scenario & Balance/Debt & Retaliation & Unconditional & $\mathrm{F} 4$ \\
\hline Skyler gives Chris some juice. Three months later, Chris gives Skyler some bread. & 0.79 & 0 & 0.08 & 0.20 \\
\hline Skyler gives Chris some juice and Chris gives Skyler some bread in return. & 0.69 & 0.28 & 0.07 & -0.03 \\
\hline Chris gives Skyler some bread. Then, Skyler gives Alex some bread. & 0.6 & -0.19 & 0.04 & -0.14 \\
\hline Skyler gives Chris a cooked lobster and Chris gives Skyler a sip of soda in return. & 0.57 & 0.14 & 0.06 & -0.06 \\
\hline $\begin{array}{l}\text { Skyler is hungry and has no food. Chris gives Skyler some bread once a week. One day, Chris } \\
\text { is thirsty and has no water. Skyler gives Chris some water. }\end{array}$ & 0.57 & -0.06 & -0.14 & 0.32 \\
\hline $\begin{array}{l}\text { Chris gives Skyler some bread and Alex sees the exchange taking place. Then, Alex gives } \\
\text { Chris some bread. }\end{array}$ & 0.42 & 0.06 & -0.05 & -0.29 \\
\hline $\begin{array}{l}\text { Skyler is hungry and has no food. Chris gives Skyler some bread. On the next day, Chris is } \\
\text { hungry and has no food. Skyler gives Chris some bread. }\end{array}$ & 0.39 & 0 & -0.22 & 0.32 \\
\hline Chris punches Skyler and Skyler punches Chris in response. & 0.06 & 0.98 & 0.01 & -0.06 \\
\hline Chris steals Skyler's bread. Three months later, Skyler steals Chris' bread. & -0.07 & 0.74 & -0.02 & 0.14 \\
\hline Skyler gives Chris some money in exchange for some bread. & 0.23 & 0.31 & -0.05 & 0.09 \\
\hline Skyler is hungry and has no food. Chris gives Skyler some bread. Skyler gives Chris a smile. & -0.01 & -0.03 & 0.64 & 0.17 \\
\hline Chris smiles at Skyler and Skyler smiles back at Chris. & -0.03 & 0.26 & 0.54 & 0.27 \\
\hline $\begin{array}{l}\text { Skyler is hungry and asks for bread from Chris every day for a week. One day, Chris is hungry } \\
\text { and asks for water from Skyler. }\end{array}$ & 0.34 & -0.09 & 0.51 & -0.08 \\
\hline Chris gives Skyler some bread without expecting anything in return from Skyler. & 0.22 & -0.14 & 0.41 & -0.22 \\
\hline Skyler steals bread from Chris. & -0.21 & 0.01 & 0.32 & -0.27 \\
\hline $\begin{array}{l}\text { Skyler spoke with Chris about his experience in class. Chris listened and told Skyler about a } \\
\text { similar experience he had as a student. }\end{array}$ & -0.01 & 0.22 & 0.24 & 0.11 \\
\hline $\begin{array}{l}\text { Chris gives a birthday present to Skyler. Three months later, Skyler gives a birthday present to } \\
\text { Chris. }\end{array}$ & 0.09 & 0.03 & 0.10 & 0.87 \\
\hline
\end{tabular}

Note. Researchers $(n=67)$ were asked "Is this reciprocity?" for each scenario $(1=$ definitely not reciprocity, $7=$ definitely reciprocity).

Numbers in bold reflect factor loadings $=<0.40$. 


\section{Table S11}

Paired-samples t-tests of reciprocity ratings (social scenarios factors)

\begin{tabular}{lcccccc}
\hline Comparison & $t(66)$ & $p$ & $M_{\text {diff }}$ & $95 \% \mathrm{Cl}$ & $d$ \\
\hline Balanced/Debt - Retaliation & 3.92 & $<0.001$ & 1.02 & 0.50 & 1.54 & 0.48 \\
Balanced/Deb - Unconditional & 13.68 & $<0.001$ & 2.19 & 1.87 & 2.51 & 1.67 \\
Retaliation - Unconditional & 4.23 & $<0.001$ & 1.17 & 0.62 & 1.72 & 0.52 \\
\hline
\end{tabular}

Note. Composites were calculated based on the three-factor solution shown in Table S9.

Analyses show comparisons after removing 18 participants who failed to report items assessing academic expertise. 


\section{Table S12}

Mean reciprocity values for the hypothetical scenarios per factor and academic field

\begin{tabular}{|c|c|c|c|c|}
\hline Factor & Field & $n$ & $M$ & $S D$ \\
\hline \multirow{6}{*}{ Balanced/Debt-based } & Anthropology & 6 & 5.08 & 1.23 \\
\hline & Biology & 16 & 4.86 & 0.75 \\
\hline & Economics & 12 & 4.40 & 1.09 \\
\hline & Psychology & 16 & 4.99 & 0.97 \\
\hline & Sociology & 5 & 5.43 & 0.83 \\
\hline & Total & 55 & 4.88 & 0.97 \\
\hline \multirow{6}{*}{ Retaliation } & Anthropology & 6 & 3.42 & 2.94 \\
\hline & Biology & 16 & 3.31 & 2.13 \\
\hline & Economics & 12 & 4.00 & 1.88 \\
\hline & Psychology & 16 & 5.16 & 1.87 \\
\hline & Sociology & 5 & 5.80 & 1.44 \\
\hline & Total & 55 & 4.24 & 2.17 \\
\hline \multirow{6}{*}{ Reputation-based } & Anthropology & 6 & 5.08 & 2.20 \\
\hline & Biology & 16 & 4.97 & 1.70 \\
\hline & Economics & 12 & 4.33 & 1.34 \\
\hline & Psychology & 16 & 4.19 & 1.95 \\
\hline & Sociology & 5 & 4.90 & 1.24 \\
\hline & Total & 55 & 4.61 & 1.71 \\
\hline \multirow{6}{*}{ Unconditional } & Anthropology & 6 & 3.67 & 2.45 \\
\hline & Biology & 16 & 2.64 & 1.04 \\
\hline & Economics & 12 & 2.65 & 1.19 \\
\hline & Psychology & 16 & 3.17 & 1.10 \\
\hline & Sociology & 5 & 3.95 & 1.74 \\
\hline & Total & 55 & 3.03 & 1.38 \\
\hline
\end{tabular}




\section{Table S13}

Frequencies of researchers' ratings of reciprocity hypothetical scenarios and level of agreement

\begin{tabular}{|c|c|c|c|c|c|c|c|}
\hline Hypothetical Scenario & $n$ & Not & Somewhat & $\begin{array}{c}\text { Is } \\
\text { Rec }\end{array}$ & $k$ & \multicolumn{2}{|c|}{$95 \% \mathrm{Cl}$} \\
\hline Skyler steals bread from Chris. & 78 & 77 & 0 & 1 & 0.97 & 0.94 & 1.01 \\
\hline $\begin{array}{l}\text { Skyler is hungry and has no food. Chris gives Skyler some bread. On the next day, Chris is } \\
\text { hungry and has no food. Skyler gives Chris some bread. }\end{array}$ & 78 & 3 & 6 & 69 & 0.78 & 0.75 & 0.81 \\
\hline $\begin{array}{l}\text { Skyler is hungry and has no food. Chris gives Skyler some bread once a week. One day, Chris is } \\
\text { thirsty and has no water. Skyler gives Chris some water. }\end{array}$ & 78 & 4 & 6 & 68 & 0.76 & 0.73 & 0.79 \\
\hline Chris gives Skyler some bread without expecting anything in return from Skyler. & 78 & 62 & 12 & 4 & 0.64 & 0.61 & 0.67 \\
\hline Skyler gives Chris some juice. Three months later, Chris gives Skyler some bread. & 78 & 12 & 6 & 60 & 0.59 & 0.57 & 0.62 \\
\hline $\begin{array}{l}\text { Chris gives a birthday present to Skyler. Three months later, Skyler gives a birthday present to } \\
\text { Chris. }\end{array}$ & 77 & 14 & 5 & 58 & 0.57 & 0.54 & 0.60 \\
\hline Skyler gives Chris some juice and Chris gives Skyler some bread in return. & 77 & 11 & 12 & 54 & 0.49 & 0.46 & 0.52 \\
\hline Skyler gives Chris some money in exchange for some bread. & 76 & 49 & 5 & 22 & 0.44 & 0.41 & 0.47 \\
\hline $\begin{array}{l}\text { Skyler is hungry and asks for bread from Chris every day for a week. One day, Chris is hungry } \\
\text { and asks for water from Skyler. }\end{array}$ & 77 & 47 & 8 & 22 & 0.39 & 0.36 & 0.42 \\
\hline $\begin{array}{l}\text { Skyler spoke with Chris about his experience in class. Chris listened and told Skyler about a } \\
\text { similar experience he had as a student. }\end{array}$ & 77 & 48 & 13 & 16 & 0.39 & 0.36 & 0.42 \\
\hline Skyler is hungry and has no food. Chris gives Skyler some bread. Skyler gives Chris a smile. & 78 & 48 & 13 & 17 & 0.38 & 0.36 & 0.41 \\
\hline Chris gives Skyler some bread. Then, Skyler gives Alex some bread. & 77 & 27 & 7 & 43 & 0.36 & 0.33 & 0.39 \\
\hline Chris steals Skyler's bread. Three months later, Skyler steals Chris' bread. & 78 & 32 & 7 & 39 & 0.33 & 0.30 & 0.36 \\
\hline Chris punches Skyler and Skyler punches Chris in response. & 76 & 27 & 10 & 39 & 0.31 & 0.28 & 0.34 \\
\hline Chris smiles at Skyler and Skyler smiles back at Chris. & 78 & 32 & 12 & 34 & 0.28 & 0.25 & 0.30 \\
\hline Skyler gives Chris a cooked lobster and Chris gives Skyler a sip of soda in return. & 77 & 31 & 14 & 32 & 0.26 & 0.23 & 0.28 \\
\hline $\begin{array}{l}\text { Chris gives Skyler some bread and Alex sees the exchange taking place. Then, Alex gives Chris } \\
\text { some bread. }\end{array}$ & 77 & 28 & 15 & 34 & 0.25 & 0.23 & 0.28 \\
\hline
\end{tabular}

Note. Kappa's in bold show scenarios that reached an above acceptable level of agreement. 


\section{Table S14}

\section{Exploratory factor analysis of scholarly definitions of reciprocity and hypothetical social scenarios}

\begin{tabular}{|c|c|c|c|c|c|c|c|}
\hline Definition/Scenario & Label & $\begin{array}{c}\text { Balanced } \\
\text { (market) }\end{array}$ & Reputation & Unconditional & $\begin{array}{l}\text { Balanced } \\
\text { (relationship) }\end{array}$ & Retaliation & Debt \\
\hline $\begin{array}{l}\text { Heteromorphic } \\
\text { reciprocity }\end{array}$ & $\begin{array}{l}\text { Exchange of things that are concretely different but of equal } \\
\text { value }\end{array}$ & 0.84 & 0.07 & 0.06 & -0.05 & 0.07 & 0.00 \\
\hline Balanced reciprocity & Transfers of equal value & 0.66 & -0.04 & 0.14 & 0.14 & 0.09 & 0.02 \\
\hline $\begin{array}{l}\text { Homeomorphic } \\
\text { reciprocity }\end{array}$ & Exchange of things that are the same & 0.62 & -0.22 & 0.03 & -0.05 & 0.07 & 0.28 \\
\hline Delayed Reciprocity & Payment with delay between initial transfer and repayment & 0.56 & -0.22 & -0.02 & 0.18 & 0.00 & 0.24 \\
\hline $\begin{array}{l}\text { Attitudinal } \\
\text { Recirpocity }\end{array}$ & $\begin{array}{l}\text { When parties mirror one another's attitudes, exchanging favors } \\
\text { on the spot }\end{array}$ & 0.50 & 0.30 & -0.03 & 0.08 & 0.21 & -0.01 \\
\hline Scenario3 & Skyler gives Chris some money in exchange for some bread. & 0.49 & -0.14 & -0.04 & 0.22 & 0.07 & -0.03 \\
\hline Reciprocal Altruismb & The trading of altruistic acts & 0.44 & 0.13 & -0.05 & 0.22 & -0.10 & 0.13 \\
\hline Reciprocity III & $\begin{array}{l}\text { Gifts exchanged immediately or on the condition that return gifts } \\
\text { will be given in the future }\end{array}$ & 0.39 & 0.13 & 0.02 & 0.11 & 0.02 & 0.39 \\
\hline Reciprocity II & $\begin{array}{l}\text { A situation where today's giving will be recompensed by } \\
\text { tomorrow's taking }\end{array}$ & 0.38 & 0.23 & -0.08 & -0.17 & 0.16 & 0.31 \\
\hline Weak Reciprocity II & A requirement that givers receive a benefit & 0.32 & 0.28 & 0.07 & 0.09 & -0.16 & 0.37 \\
\hline Reciprocation & $\begin{array}{l}\text { Action or practice of offering a response in kind, or of doing one } \\
\text { thing in return for another }\end{array}$ & 0.29 & 0.04 & -0.05 & 0.28 & 0.06 & 0.23 \\
\hline $\begin{array}{l}\text { Interpersonal } \\
\text { Reciprocity }\end{array}$ & $\begin{array}{l}\text { The process of behavioral adaptation in which one responds, in } \\
\text { similar direction, to a partner's behaviors with behaviors of } \\
\text { comparable functional value }\end{array}$ & 0.27 & 0.06 & 0.07 & -0.07 & 0.21 & 0.09 \\
\hline Scenario9 & $\begin{array}{l}\text { Chris gives Skyler some bread and Alex sees the exchange } \\
\text { taking place. Then, Alex gives Chris some bread. }\end{array}$ & 0.00 & 0.78 & -0.03 & -0.02 & 0.00 & -0.02 \\
\hline Reciprocal Altruism ${ }^{\mathrm{a}}$ & $\begin{array}{l}\text { Acting altruistically towards another who has already acted } \\
\text { altruistically }\end{array}$ & -0.09 & 0.75 & 0.03 & 0.14 & 0.10 & 0.13 \\
\hline $\begin{array}{l}\text { Upstream indirect } \\
\text { reciprocity }\end{array}$ & $\begin{array}{l}\text { An act of altruism causes the recipient to perform a later act of } \\
\text { altruism in the benefit of a third party }\end{array}$ & -0.11 & 0.73 & 0.11 & -0.13 & 0.10 & 0.21 \\
\hline $\begin{array}{l}\text { Generalized } \\
\text { reciprocity II }\end{array}$ & $\begin{array}{l}\text { General tendency to be altruistic to others when others have } \\
\text { been altruistic to you }\end{array}$ & 0.11 & 0.68 & -0.03 & 0.11 & 0.04 & -0.18 \\
\hline Positive reciprocity & An action that has a positive effect upon someone else is repaid & 0.04 & 0.57 & 0.09 & 0.15 & 0.04 & 0.04 \\
\hline
\end{tabular}


with an action that has approximately equal positive effect upon another

Downstream The performer of an act of altruism is more likely to be the indirect reciprocity recipient of a later act of altruism

Indirect reciprocity When return is expected from someone other than recipient of benefit

Scenario10 Chris gives Skyler some bread. Then, Skyler gives Alex some bread.

Symmetry-based reciprocity

When mutual affection between two parties prompts similar behavior in both directions without the need to keep track of give-and-take, so long as the relationship remains satisfactory

Network reciprocity Non-conditional altruism favored by selection on social

Generalized

reciprocity I networks

Scenario13

Non-conditional sharing and giving of assistance

Skyler is hungry and has no food. Chris gives Skyler some bread. Skyler gives Chris a smile.

Strong reciprocity II Non-conditional altruism and punishment favored by group selection

Negative

Reciprocity

\section{Acquisition of benefit without intent to repay}

Scenario12

Scenario6

Chris gives Skyler some bread without expecting anything in return from Skyler.

Chris smiles at Skyler and Skyler smiles back at Chris.

Skyler spoke with Chris about his experience in class. Chris

Scenario17 listened and told Skyler about a similar experience he had as a student.

Scenario16 Skyler steals bread from Chris.

\begin{tabular}{lll}
\hline Scenario8 & Skyler gives Chris some juice. Three months later, Chris gives & -0.22 \\
& Skyler some bread.
\end{tabular}

Scenario1 Skyler gives Chris some juice and Chris gives Skyler some bread in return.

Skyler is hungry and has no food. Chris gives Skyler some

Scenario14 bread once a week. One day, Chris is thirsty and has no water. Skyler gives Chris some water.

Scenario2
0.07

0.10

0.54

0.09

0.17

$-0.12$

0.26

0.06

0.53

0.08

0.16

$-0.05$

0.24

0.14

0.26

$-0.25$

$-0.01$

0.23

0.31

0.20

$-0.14$

$0.24-0.15$

0.19

0.24

0.67

$-0.08$

$-0.02$

$-0.18$

0.28

0.12

0.60

$-0.18$

0.01

0.12

$-0.07$

$-0.23$

0.57

$-0.02$

0.05

$-0.10$

0.15

0.50

0.27

0.11

0.12

$-0.21$

0.06

0.08

0.50

$-0.02$

$-0.16$

0.05

$-0.14$

0.09

0.48

0.17

$\begin{array}{ll}-0.15 & 0.00\end{array}$

$-0.09$

0.45

0.25

$0.38 \quad 0.08$

0.22

$-0.07$

0.30

0.15

$0.13-0.08$

$-0.22-0.08$

0.28

0.03

0.90

$\begin{array}{ll}0.02 & -0.10 \\ 0.02 & -0.04\end{array}$

0.29

0.17

$-0.04$

0.63

0.10

$-0.12$

$-0.12$

0.06

$-0.18$

0.58

0.04

0.32

0.13

0.03

0.49

0.10

$-0.01$ 


\section{of soda in return.}

Scenario7 Chris gives a birthday present to Skyler. Three months later Skyler gives a birthday present to Chris.

Skyler is hungry and asks for bread from Chris every day for a

Scenario15 week. One day, Chris is hungry and asks for water from Skyler.

Skyler is hungry and has no food. Chris gives Skyler some

Scenario4 bread. On the next day, Chris is hungry and has no food.

Skyler gives Chris some bread.

When the return benefit for a beneficent act is a by-product or

Pseudoreciprocity incidental effect of egoistic behavior by the recipient of the beneficent act

\begin{tabular}{|c|c|c|c|c|c|c|c|}
\hline Scenario7 & Skyler gives a birthday present to Chris. & 0.10 & -0.29 & 0.15 & 0.47 & 0.22 & 0.20 \\
\hline Scenario15 & $\begin{array}{l}\text { Skyler is hungry and asks for bread from Chris every day for a } \\
\text { week. One day, Chris is hungry and asks for water from Skyler. }\end{array}$ & -0.15 & 0.04 & 0.31 & 0.42 & -0.05 & 0.24 \\
\hline Scenario4 & $\begin{array}{l}\text { Skyler is hungry and has no food. Chris gives Skyler some } \\
\text { bread. On the next day, Chris is hungry and has no food. } \\
\text { Skyler gives Chris some bread. }\end{array}$ & 0.23 & -0.03 & -0.16 & 0.41 & -0.02 & 0.01 \\
\hline Pseudoreciprocity & $\begin{array}{l}\text { When the return benefit for a beneficent act is a by-product or } \\
\text { incidental effect of egoistic behavior by the recipient of the } \\
\text { beneficent act }\end{array}$ & -0.03 & 0.26 & 0.30 & 0.29 & -0.09 & 0.08 \\
\hline Scenario5 & $\begin{array}{l}\text { Chris steals Skyler's bread. Three months later, Skyler steals } \\
\text { Chris' bread. }\end{array}$ & 0.02 & -0.04 & 0.00 & -0.01 & 0.89 & 0.08 \\
\hline Scenario11 & Chris punches Skyler and Skyler punches Chris in response. & 0.08 & 0.06 & -0.02 & 0.14 & 0.83 & -0.17 \\
\hline Negative rec. II & $\begin{array}{l}\text { An action that has a negative effect upon someone else is } \\
\text { repaid with an action that has approximately equal negative } \\
\text { effect upon another }\end{array}$ & -0.11 & 0.19 & 0.07 & -0.26 & 0.54 & 0.16 \\
\hline Tit-forTat reciprocity & $\begin{array}{l}\text { When individuals cooperate if the other party cooperates, and } \\
\text { defect if the other party defects }\end{array}$ & 0.16 & 0.10 & -0.30 & -0.02 & 0.38 & 0.27 \\
\hline Direct Reciprocity & When return is expected from the recipient of the benefit & 0.04 & 0.13 & -0.05 & 0.01 & 0.02 & 0.74 \\
\hline $\begin{array}{l}\text { Calculated } \\
\text { reciprocity }\end{array}$ & $\begin{array}{l}\text { When individuals keep track of the benefits they exchange with } \\
\text { particular partners, which helps them decide to whom to return } \\
\text { favors }\end{array}$ & 0.14 & 0.14 & -0.15 & 0.01 & 0.04 & 0.63 \\
\hline $\begin{array}{l}\text { Risk reduction } \\
\text { reciprocity }\end{array}$ & Giving with the expectation of equivalent return & 0.30 & -0.05 & 0.30 & 0.03 & -0.15 & 0.53 \\
\hline Reciprocity I & $\begin{array}{l}\text { A chain of gifts and counter gifts, which in the long run balance, } \\
\text { benefiting both sides equally }\end{array}$ & 0.16 & 0.15 & 0.12 & 0.02 & 0.24 & 0.49 \\
\hline $\begin{array}{l}\text { Contingent } \\
\text { Reciprocity }\end{array}$ & Giving that is contingent on past giving & 0.06 & 0.12 & -0.19 & 0.08 & 0.09 & 0.48 \\
\hline
\end{tabular}

Note. Researchers $(n=68)$ were asked "Is this reciprocity?" for each scenario $(1=$ definitely not reciprocity, $7=$ definitely reciprocity).

Numbers in bold reflect factor loadings $=<0.40$. 


\section{S2. Qualitative expert responses of the term reciprocity}

In this following section we report on all of the qualitative responses researchers provided to the question: What is reciprocity?

\section{Anthropology}

Eric Sabourin-- Exchange may tend to be reduced to a simple permutation of objects, releasing each part of any debt and any links, when reciprocity is a reversible relationship between subjects. It is a relationship motivated by an interest in the other by the production of social ties.

\section{Biology}

Dalila Bovet-- I think that we observe reciprocity among animals when the gift of some food, or another favor, increases the probability for the donor to receive the same thing, or something else, from the receiver.

Gabriele Schino-- In my opinion, the term reciprocity is useful as an umbrella term that includes both partner control [by this is meant actions that each partner makes independent of another, where one tries to influence the other by incentivizing or punishing, e.g., in an iterated prisoner's dilemma] and partner choice [removes the need to punish or incentivize partner, agents choose based on the capacity and willingness of a partner to provide benefits]. It is essential, however, to make clear the distinctiveness of the two processes. If you are interested, you may find these thoughts elaborated in a paper of mine: Schino G., Aureli F. (2017) Reciprocity in group-living animals: partner control versus partner choice. Biological Reviews 92: 665-672.

Gerald Carter-- I wrote these as a PhD student:

1. https://socialbat.org/2012/06/04/reciprocity-and-reciprocal-altruism-in-biology/ 2.https://socialbat.org/2015/12/08/how-we-define-reciprocity-the-good-the-broadand-the-ugly/

My thoughts evolved a bit since then, but not too much. Direct reciprocity occurs when an organism makes cooperative investments that are in some way contingent on the experience (or memory) of cooperative returns from the recipient. This behavior requires repeated interactions, cognition, and in most cases, individual recognition. I call this definition "good" because I believe it is most in line with what Trivers meant by reciprocal altruism. A broader usage of reciprocity says that it occurs when an organism makes cooperative investments in a recipient that are in some way contingent on cooperative returns from the recipient, regardless of the mechanism. Note that this does not require cognition. So even plants and fungi can perform this version of reciprocity. This has also been called reciprocal rewards, sanctions, partner choice, or reciprocation. I like this definition too, although it means that all enforced forms of mutual benefits are a form of reciprocity. Some people define reciprocity as when organisms make cognitively calculated cooperative investments based on the cognitive expectation of the cooperative returns from the recipient. I call this the ugly definition because, although common, it's a distortion of the original concept, it's not what we should 
expect animals to do, and it's not really even what humans do most of the time in their social lives, unless they are nasty Machiavellian psychopaths.

Michael Taborsky-- Reciprocity is essentially a proximate (i.e. mechanistic) concept implying decision rules evolved through certain cost/benefit relationships. At the ultimate (i.e. evolutionary) level, this term refers to an apparently cooperative trait or behaviour that benefits a receiver of the act at immediate costs to the actor. At the same time, it increases the probability to receive benefits in return, from the same or different partners. Reciprocation is hence intrinsically altruistic and prone to cheating. At the proximate level, there are three forms of reciprocity with different decision rules:

Generalized reciprocity: help anyone if helped by someone

Direct reciprocity: help someone who has helped you before

Indirect reciprocity: help someone who is helpful.

Ronald Noë-- Why I prefer defining verbs rather than nouns. Terms such as reciprocity, cooperation and mutualism can certainly be useful as shorthand in descriptive accounts of outcomes of (series of) interactions that are mutually beneficial to the agents involved. They can also be defined in such a way that they convey information about the agents involved (e.g. cooperation applies to intraspecific interactions and mutualism to inter-specific interactions), or about the temporary structure (e.g. cooperation applies interactions with simultaneous benefit, while reciprocity applies to cases in which the agents involved take turns), or any other attribute of interest. Those interested in the evolution of adaptations that make such mutually beneficial outcomes possible need something else, however: definitions of actions. When agents attempt to help each other multiple times, natural selection will 'judge' the effect of all attempts, successful or not, on each agent's fitness. Those 'agents' will most often be individual organisms, but might also be some other entity, such as a group of people or a colony of eusocial insects, that chooses among multiple possible actions on the basis of a 'strategy'. These strategies, algorithms that determine which action the agent chooses under all possible circumstances, are the real targets of natural and cultural selection. Depending on the species at hand, they can be implemented by all kinds of mechanisms, e.g. cognitive, physiological, chemical processes, or whatever. In short: we need definitions of the visible outcomes of these strategies: the actions of agents. Agents cannot cooperation or reciprocity, but they can cooperate or reciprocate, so let's concentrate on the definition of verbs rather than nouns. An alternative for fans of nouns is to use nouns that describe the essence of the actions of interest e.g. describe an action of $X$ that momentarily lowers $X$ 's fitness and is potentially beneficial to $Y$ as an 'investment' by $X$ in $Y$, even though ' $X$ invests in $Y$ ' would still be simpler. The problem we are probably all most interested in is the evolution of strategies that, as a rule, result in a net benefit for agents that invest in other agents. An investment without an immediate return resulting in net benefit during a single interaction is more commonly known as an 'altruistic act'. The problem with 'altruism' is again that it is defined as an outcome rather than an action. An investment can be defined, in contrast, independent of the way in which it is embedded in the temporary structure of actions: before, during or after an action by the receiver of the investment, but also in the absence of any action of the receiver. Correctly defined, it remains one and the same action independent of context and thus a genuine target of selection. 


\section{Economics}

Ernst Fehr-- In my view, reciprocity should be conceptualized in three different ways: 1) Reciprocal strategies in repeated games (then it is not simply a behavior but a HISTORY CONTINGENT STRATEGY). Some of your questions have a bearing on this. 2) A social norm, i.e., a NORMATIVE OBLIGATION to respond to a favour (positive reciprocity) or an insult (negative reciprocity). None of your questions captures this. 3) An INDIVIDUAL PREFERENCE to respond to kind acts with kind acts and to unkind acts with unkind acts. Note, here reciprocity is also not just a behavior but a preference.

Simon Gaechter-- At the behavioral level, reciprocity is a pattern of behavior that responds to a beneficial act one has received with an act that is beneficial for the person (or group of people) whose beneficial act one has enjoyed in the first place. This is positive reciprocity and can be spaced out in time. An equivalent definition can hold for harmful acts: this is negative reciprocity. The starkest example occurs in anonymous one-shot settings, where there is no strategic incentive to reciprocate: this is genuine reciprocity. In strategic settings reciprocity can be confounded with purely egoistic, transactional incentives, that is, even people with no pro-social motivations whatsoever can behave reciprocally if it furthers their (long-run) strategic incentives, including incentives for being in good standing (reputation, indirect reciprocity).

Urs Fischbacher-- I think that my view is shared by many people (many references are required), and the formulation is rather sloppy. So a somewhat less sloppy comment is here: "There is a general rule to be good to good people (positive reciprocity) and to be bad to bad people (negative reciprocity) but the direction of the good and bad action can vary: direct reciprocity $(A->B==>B->A)$, indirect reciprocity $(A->B==>C->A)$, and generalized reciprocity $(A->B==>B->C)$. In addition, reciprocity can be based on the action, and it can be based on the preferences. It is clear to me that you are aware of all (or many) forms of reciprocity and try to tease out what people think about it. When thinking about it in science, I and probably many other behavioral scientists are aware of the differences and have difficulty answering the question about whether something is reciprocity. Many of your examples are in line with a specific form of reciprocity but not with another, and at least I am reluctant to restrict to one of the several definitions.

\section{Evolutionary social science}

Matt Zefferman-- I am fine with different uses of the term "reciprocity" as a useful shorthand in scientific papers as long as the authors' clarify their meaning. Where this becomes problematic is when the authors' aim is to pit "reciprocity" against "something else" in the evolution of cooperation. This focuses the results on the semantics instead of the actual mechanisms.

\section{Mathematics}

Fabio Chalub-- Human reciprocity is related to "intent", which I think was not clear in the questions asked in this survey. For non-human interactions, things are naturally much more complicated. 
Mike Mesterton-Gibbons-- My substantive thoughts on reciprocity are essentially all contained in four different passages of the forthcoming 3rd edition of my Introduction to Game-Theoretic Modelling... Below are the relevant paragraphs. We now proceed to investigate possible escapes from the paradox of the prisoner's dilemma. An important idea in this regard is that of reciprocity: one good turn deserves another, and one bad turn deserves another, too. To be more precise, reciprocity in the sense of reciprocal altruism [11, 337, 338] means that one good turn now deserves another later, and similarly for bad turns. Thus reciprocity is an inherently dynamic concept: it is impossible to reciprocate if the game is played only once, and so we shall assume that it is played repeatedly. Indeed it is convenient to define a brand new game, of which a single play consists of all the plays of the prisoner's dilemma that an individual makes within some specified interval of time. We call this brand new game the iterated prisoner's dilemma, or IPD; and whenever a prisoner's dilemma is embedded in an iterated prisoner's dilemma, we shall refer to each play of the prisoner's dilemma as a move of the IPD... Note, finally, that there is no difference in principle between cooperation against a common enemy and cooperation towards a common end (for much the same reason that minimizing a function is the same as maximizing its negative). In either case, cooperation is an incidental consequence of ordinary selfish behavior; and so this category of cooperation is known to biologists as a byproduct mutualism [50, 217], or simply mutualism [67, 68]. What distinguishes reciprocity from mutualism is the presence or absence of scorekeeping. For reciprocators, benefits are conferred or costs extracted by specific individuals, and it is necessary to keeps tabs on their past behavior. For mutualists, by contrast, benefits are conferred or costs extracted by the common environment "both players and non-players" with which all interact; even if scorekeeping is possible it is unnecessary, because the risk is too high that anyone who tries to exploit others for short-term gain will only penalize herself. In other words, although there is no direct feedback between individuals only indirect feedback from the environment benefits exceed costs over the time scale on which rewards are measured, and so there is no incentive to cheat... In sum, despite the plenitude of categories into which cooperation has been subdivided by various authors, this chapter demonstrates that there is really only one escape from the prisoner's dilemma, and that is to discover that the game being played or, in experiments, the game that subjects perceive themselves as playing is not really the prisoner's dilemma after all. In other words, if $A$ is the payoff matrix, strategy 1 is cooperative, strategy 2 is non-cooperative and there appears to exist a time scale over which a21 > a11 then, when all relevant factors are accounted for, either that appearance must turn out to have been an illusion, or else there must exist a longer time scale over which a11 > a21, and which is also the relevant time scale for tallying benefits and costs [218]. Nevertheless, the details may differ significantly in different cases, and game-theoretic models help us to unravel them. Despite that, cooperation via the status-enhancement effect in ravens is reminiscent of what has been called indirect reciprocity [6]. Here two remarks are in order. First, if one regards mutualism and reciprocity as the poles of a grand continuum, then the degree of feedback between cooperators should steadily increase between the first pole and the second; any behavior described as a form of reciprocity should be close to the second pole. Second, there is no central authority to act as supreme arbiter of names for sub-categories. As a result, indirect reciprocity means different things to different people: either that a well defined network of specific donors and recipients contains more than two individuals [41], or that individuals can enhance 
their status through generosity and be more generous to partners of higher status $[6,256]$. The first interpretation is far closer to reciprocity, especially for a short network; and the second interpretation which does not require the same two individuals ever to meet again [256, p. 573] is so close to mutualism that, in one opinion, it stretches the definition of reciprocity to the point of meaninglessness [369, p. 149].

\section{Philosophy}

Andrew Lister-- think of reciprocity as a non-instrumental tendency to respond in kind. That would be reciprocity as a psychological phenomenon. From a normative perspective, it can a duty (to return benefits), but also a limit or condition on other duties, duties not rooted in receipt of benefit. I'm interested in the conditionality of (some) of our duties to others.

\section{Psychology}

Dave Kenny-- I humbly suggest you look at pages 418-420 in Kenny, Kashy \& Cook, Dyadic Data Analysis. [Gottman and colleagues' (1998) negative spirals are good examples of reciprocity: Mary says something negative to Mike, and Mike then says something negative to Mary. Perhaps the best statistical definition of reciprocity is a partner effect in the sequential APIM that we discussed... the cocycling of two individuals' responses is the penultimate expression of synchronicity. Alternatively, the temporal coordination of behavior can be operationalized as the contemporaneous correlation of two individuals' responses within time-series regression analyses and as partner effects among these variables. This analysis, however, should not be used if the responses of individuals cycle. In either case, synchrony implies that the behavior of two people is coordinated (simultaneously or sequentially) on the basis of the same "clock"].

\section{Sociology}

Jose A. Noguera-- Reciprocity in my view is conditional cooperation/punishment in general, that is, conditional to previous or expected cooperation/punishment by the relevant subjects or type of subjects. So there might be a lot of different sub-types of reciprocity (direct vs diffuse, delayed vs simultaneous, proportional vs non proportional, material vs symbolic goods interchange, market exchange vs nonmarket exchange, etc.). The key issue is conditionality to previous or expected similar behaviour. 